\title{
DIREITO JURISPRUDENCIAL E AUTONOMIA DO DIREITO NAS ESTRATÉGIAS DISCURSIVAS DA CIÊNCIA JURÍDICA ENTRE OS OITOCENTOS E OS NOVECENTOS*
}

\author{
CASE LAW AND AUTONOMY OF THE LAW ON THE DISCURSIVE STRATEGIES OF
}

JURISPRUDENCE BETWEEN THE NINETEENTH AND TWENTIETH CENTURIES

\section{DIRITTO GIURISPRUDENZIALE E AUTONOMIA DEL DIRITTO NELLE STRATEGIE DISCORSIVE DELLA SCIENZA GIURIDICA TRA OTTO E NOVECENTO}

\begin{abstract}
RESUMO: No curso dos dois séculos nos quais os regimes jurídicos da legalidade encontraram desenvolvimento, frequentemente ressurgiam questões relativas às relações entre direito $\mathrm{e}$ sociedade, ao grau de ancoramento às opções do legislador e ao valor sistemático a se reconhecer ao fator jurisprudencial. $\mathrm{O}$ advento do primado da lei colocou o problema de sua sustentabilidade. O objetivo destas páginas é seguir alguns itinerários teóricos oitocentistas e novecentistas sobre como conceber, por meio da jurisprudência, dinâmicas de manifestação do direito autônomas da mediação do poder político. $\mathrm{O}$ tema tem uma sua relevância também para uma compreensão da fase atual; nessa, de fato, como se procurará demonstrar, parece se delinear um horizonte diverso de sentido para a autonomia do direito em respeito aquele passado recente. Proceder-se-á considerando as percepções doutrinais de duas questões correlatas: as características da interpretação do direito por um lado e os perfis sistemáticos da jurisdição do outro.

RIASSUNTO: Nel corso dei due secoli in cui i regimi giuridici della legalità hanno trovato svolgimento sono spesso tornate a proporsi le questioni relative al rapporto tra diritto e società, al grado di ancoraggio alle opzioni del legislatore e al valore sistematico da riconoscere al fattore giurisprudenziale. L'avvento del primato della legge ha posto il problema della sua sostenibilità. Intento di queste pagine è seguire alcuni itinerari teorici ottonovecenteschi sul come concepire, tramite la giurisprudenza, dinamiche di manifestazione del diritto autonome dalla mediazione del potere politico. Il tema ha una sua rilevanza anche per una comprensione della fase attuale; in essa infatti, come si cercherà di mostrare, sembra delinearsi un diverso orizzonte di senso per l'autonomia del diritto rispetto a quel passato recente. Si procederà considerando le percezioni dottrinali di due questioni correlate: i caratteri dell'interpretazione del diritto da un lato e i profili sistematici della giurisdizione dall'altro.
\end{abstract}

PALAVRAS-CHAVE: Ciência jurídica oitocentista e novecentista. Primado da Lei. Autonomia do Direito. Interpretação do direito. Perfis sistemáticos da jurisdição.
PAROLE-CHIAVE: Scienza giuridica otto-novecentesca. Primato della legge. Autonomia del diritto. Interpretazione del diritto. Profili sistematici della giurisdizione.
ABSTRACT: In the span of the two centuries in which the legal regimes of legality found development, it often resurfaced the issues related to the relations between law and society, to the degree of anchorage to the lawmaker choices, and to the systematic value to be recognized to the case law factor. The advent of the primacy of law has placed the issue of it sustainability. The purpose of these pages is to follow some theoretical itineraries from the Nineteenth and Twentieth Centuries about how to conceive, through case law, a dynamics of law's manifestation autonomous from political power mediation. The subject has its own relevance for an understanding of the current phase; on this, in fact, as I will seek to demonstrate, it seems to draw a diverse horizon of sense to the Law's autonomy compared to the recent past. I shall proceed by considering the doctrinal perceptions of two correlate questions: the characteristics of law's interpretation on the one hand, and the systematic profiles of jurisdiction on the other.

KEYWORDS: Nineteenth and Twentieth Centuries jurisprudence; primacy of the law; autonomy of the law; interpretation of the law; systematic profiles of jurisdiction.

\footnotetext{
* Publicação original: MECCARELLI, Massimo. Diritto giurisprudenziale e autonomia del diritto nelle strategie discorsive della scienza giuridica tra Otto e Novecento. Quaderni fiorentini per la storia del pensiero giuridico moderno, XL, pp. 721-745, 2011. Tradução de Régis João Nodari, mestrando em Direito pela Universidade Federal do Rio Grande do Sul (UFRGS), com a autorização do autor.

*** Jurista e Historiador do direito. Professor da Universidade de Macerata. Coordenador da disciplina de História do Direito na Universidade de Macerata, Itália. Pesquisador associado no Max-Planck-Institut für europäische Rechtsgeschichte (MPIeR), Alemanha.
} 


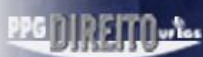

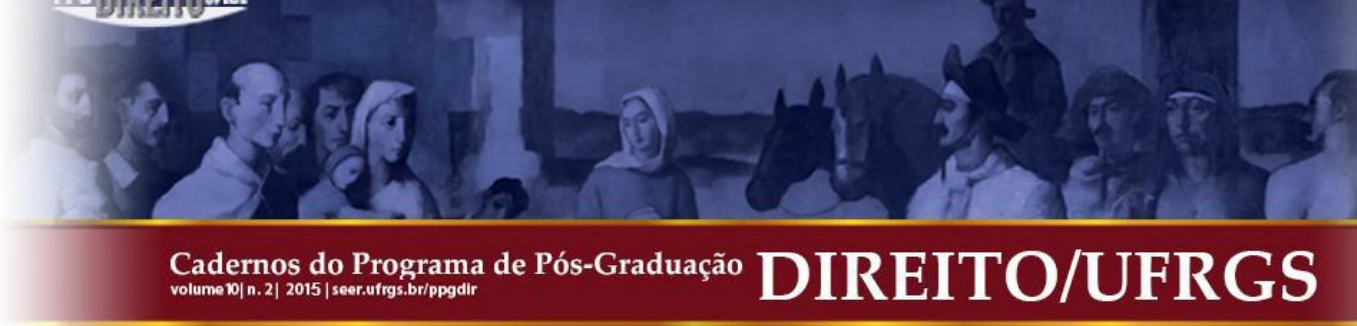

SUMÁRIO: 1 . O debate sobre os métodos de interpretações da Lei. 2. Autonomia do Direito e horizonte monístico. 3. A jurisprudência das Cortes supremas como fator de estabilização: uma comparação entre França, Alemanha e Itália. 4. A fase atual: além do horizonte monístico uma nova perspectiva de sentido para a autonomia do direito. Referências.

\section{O DEBATE SOBRE O MÉTODO DE INTERPRETAÇÃO DA LEI}

Os percursos do pensamento jurídico relacionado ao método de interpretação do direito no século XIX são muito complexos e somente aceitando um certo grau de simplificação se pode propor deles uma classificação sintética. Todavia, aqui nos interessa individualizar, na multiplicidade das orientações, algumas tendências mais genéricas. É possível considerar duas diversas polarizações.

Uma primeira distingue entre as aproximações que visam a abordagem de “implementar" e as aproximações que visam a abordagem de "inovar" o direito positivo. Tal distinção permite observar a nota dialética entre formalismo de caráter pandectístico e antiformalismo de inspiração variadamente jusliberal, fazendo referência ao diverso significado atribuído a revaloração do papel do jurista com respeito ao ordenamento normativo.

Através da atividade de implementação a ciência jurídica é reconhecida como espaço hermenêutico do qual realiza o processo de afirmação do primado da lei e de introdução da forma do código. Simplificando o discurso podemos dizer que sob o plano epistemológico isto determinou um fechamento formalístico do saber jurídico; sob o plano axiológico implicou uma adesão (sob o véu da neutralidade da ciência) aos princípios veiculados pelo legislador através do direito positivo, sob o plano estratégico produziu uma atividade de construção dogmática do sistema sobre a lei, colocada à custódia da concepção individualística do direito privado.

As abordagens tendentes à inovação, ao revés, pretenderam valorizar o momento hermenêutico elevando-o a atividade capaz de incidir sobre conteúdos e orientações ideológicas do direito, em resposta às mutações da sociedade. A interpretação aqui se tornava sobretudo um momento valorativo, desconstrutivo e somente depois reconstrutivo. Tratava-se de descobrir o direito em formação desde a base, para erguer e sustentar a sua construção. Isto favoreceu uma abertura da ciência jurídica para outros saberes capazes de revelar tendências e carácteres da sociedade e uma disponibilidade para acolher no ordenamento vigente princípios e valores não alinhados com aqueles originariamente escolhidos pelo legislador. O objetivo estratégico era de fato aquele de promover uma concepção social do direito privado, seja no 


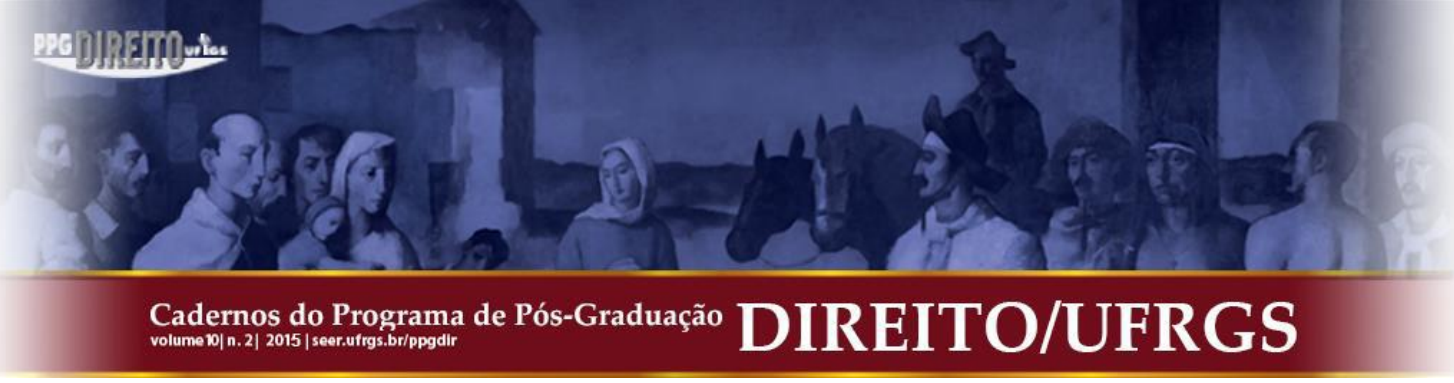

sentido de uma recuperação de orientação solidarística, seja naquele de uma acentuação de funcionalidade a respeito dos processos econômicos complexivos do capitalismo industrial.

Há, porém, uma outra polarização, que, opina-se aqui, faz emergir um cenário mais complexo, esse consiste em distinguir entre as atitudes a respeito do princípio da legalidade: algumas doutrinas entendiam colocá-lo em discussão, outras consideravam irrenunciável pressupô-lo e confirmá-lo.

Vistos sob tal luz, as abordagens inovativas não aparentam tão unitárias e distintas das abordagens meramente implementativas. A prospectiva programática da inovação vinha de fato a refratar-se por meio do prisma dos modos possíveis com os quais encontrar a realização. Trata-se de decidir de que modo se daria espaço a um processo de liberalização do direito da lei: precisaria dar-lhe uma evidencia sob o plano das fontes ou seria mais oportuno obtê-lo somente no nível hermenêutico e no sinal do primado da lei?

Compreender estas dúvidas sobre o método, é, a nosso ver, decisivo, porque é nele que se conotam espaços e natureza do direito jurisprudencial naquele contexto de experiência jurídica; tanto mais quando se considera que as abordagens que fazem mais brecha no debate são claramente aquelas do segundo tipo, prudentes sob o ponto das fontes, mas não renunciam a um projeto de reescrita dos conteúdos do direito em relação à sociedade.

Concentramo-nos, portanto, sob as estratégias discursivas que tendem a realizar a recuperação do direito jurisprudencial, colocando-se na perspectiva metodológica da interpretação evolutiva da lei. Trata-se de uma característica fundamental que, ainda que desenvolvida e declinada em modos diversos, é recorrente na Itália do final dos Oitocentos, mas também na Europa teve sua difusão, pense-se nas teses de Rudolf von Jhering, Josef Kholer, Raymond Saleilles ou Eugen Huber, somente para fazer alguns exemplos ${ }^{1}$.

\footnotetext{
1 Para qualquer referência bibliográfica sob este panorama da composição de posições teóricas, além destes ensaios é possível ver citações a seguir neste parágrafo, lembramos também WIEACKER, Franz. Storia del diritto privato moderno. v. II. Milano: Giuffrè, 1980, p. 306. MANAI, Dominique. Eugen Huber jurisconsulte charismatique. Bäie, Frankfurt am Main: Helbing \& Lichtenhahn, 1990; CARONI, Pio. Il mito svelato: Eugen Huber. Zeitschrift für schweizerisches Recht, n. 132, 1991, p. 381-492; SPECIALE, Giuseppe. Antologia giuridica. Laboratori e rifondazioni di fine Ottocento. Milano: Giuffrè, 2001; PETIT, Carlos. Lambert en la Tour Eiffel, o el derecho comparado de la Belle Epoque. La comparazione giuridica tra Ottocento e Novecento. In memoria di Mario Rotondi. Milano: Istituto lombardo di scienze e lettere, 2001, p. 53-98; HESPANHA. Antonio Manuel. Introduzione alla storia del diritto europeo. Bologna: il Mulino, 2003, p. 258 et seq.; RUCKERT, Joachim. Der Geist des Rechts in Jherings"Geist" und Jherings "Zweck". Rechtsgeschichte, n. 5, 2004, p. 128-149 e n. 6, 2005, p. 122-142; SABBIONETI, Marco. Un Cattolico "Protestante". La crisi della separazione tra Stato e Chiesa nelle lettere inedite di Raymond Saleilles a Louis Birot (1906-1909). Torino: Giappichelli, 2005; ARAGONESES, ALFONS. Recht im "fin de siècle". Briefe von Raymond Saleilles an Eugen Huber (1895-1911). Frankfurt am Main: Klostermann, 2007; Id. Un jurista del Modernismo. Raymond Saleilles y los orìgenes del derecho comparado. Madrid: Universidad Carlos III de
} 


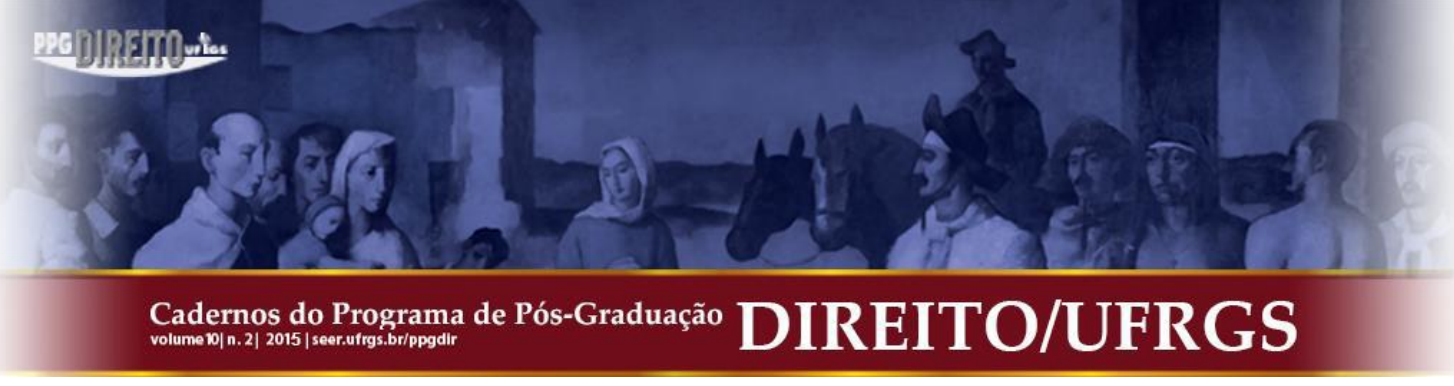

Aqui, se o sistema das fontes permanece dominado pela lei, o ordenamento jurídico vem concebido como alguma coisa de maior extensão que o mero conjunto do direito positivo. A interpretação em tal horizonte não tende a reconstruir a vontade originária do legislador, mas é pensada como "o estudo da própria vida social", que serve para "completar a lei", descobrindo "aquilo que é latente nela"2. A interpretação pode absorver tal tarefa sabendo colher as tendências do direito em formação na consciência popular e nas relações sociais.

Este novo direito permanece, porém, um todo único com a lei. Esta, explicavam, "separa-se, dizemos assim, do seu autor; fala uma linguagem própria, não aquela de quem a

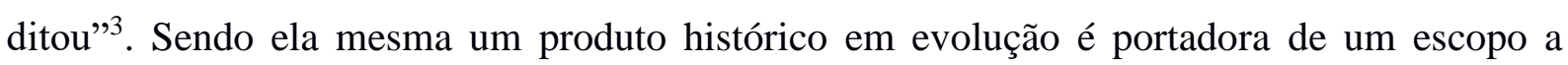
perseguir, mais que um conteúdo pré-definido ${ }^{4}$; é o escopo que, graças às declinações sempre atualizadas que a interpretação consegue fazer dela, tem em conexão a lei com a sociedade e as suas necessidades.

O novo direito em formação embora proveniente do exterior, não se afirma, portanto, fora da norma positiva ${ }^{5}$; um pouco ele representa um momento da vida da norma legal que se torna manifesto através da re-definição jurisprudencial da norma legal.

A construção do campo de evolução jurisprudencial do ordenamento é tecnicamente obtida com os assim ditos órgãos respiratórios da lei: as cláusulas gerais, isto é, aqueles conceitos não definidos e não completamente definíveis "para os quais atingimos critérios que estão fora da própria lei”6; os princípios gerais do direito, se concebidos, embora segundo

Madrid, 2009.

2 SIMONCELLI, Vincenzo. Le presenti difficoltà della scienza del diritto civile (1890). In: SIMONCELLI, Vincenzo. Scritti giuridici. v. I. Roma: Foro italiano, 1938, p. 424.

3 BRUGI, B. Della proprietà. v. I. Napoli-Torino: Marghieri, UTE, 1911, p. 7; Id., Di un fondamento filosofico della così detta interpretazione storica delle leggi. Studi storici e giuridici dedicati ed offerti a Federico Ciccaglione nella ricorrenza del XXV anniversario del suo insegnamento. v. II. Catania: Giannotta, 1910, p. 47. Assim também SIMONCELLI, Vincenzo. Le presenti difficoltà. op. cit., p. 431; MORTARA, Lodovico. Commentario del codice e delle leggi di procedura civile. 2. ed. v. I. Teoria e sistema della giurisdizione civile. Milano: Vallardi, (s.d.), § 75, p. 81; COVIELLO, Leonardo. Dei moderni metodi d'interpretazione della legge. S. Maria C. V.: Cavotta, 1908, p. 9-10; DEGNI, Francesco. L'interpretazione della legge. Napoli: Jovene, 1909, p. 160, et seq.; POLACCO, Vittorio. Penombre e sorprese nella formazione delle leggi (1914). In: POLACCO, Vittorio. Opere minori. Parte prima, Problemi di legislazione. Modena: Università degli Studi di Modena, 1928, p. 69-78; COVIELLO, Nicola. Manuale di diritto civile italiano. Milano: Società Editrice Libraria, 1915, p. 71-72; FERRARA, Francesco. Potere del legislatore e funzione del giudice. Rivista di diritto civile, n. III, 1911, p. 512, et seq.

4 Vejam-se por exemplo CoviEllo, L. Dei moderni metodi. op. cit., p. 32-35; BRUGI, B. Di un fondamento filosófico. op. cit., p. 8; Id., L'abuso del diritto nel progetto di codice delle obbligazioni e dei contratti. Studi in onore di Alfredo Ascoli. Messina: Principato, 1931, p. 83; MORTARA, L. Commentario. op. cit., p. VII.

5 Sendo a lei uma "produção orgânica secular" explica SIMONCELLI, Vincenzo. Le presenti difficoltà. op. cit., p. 424, todos desenvolvimentos não podem senão partir do direito positivo vigente.

6 BRUGI, B. I principii generali del diritto e il diritto naturale. Archivio giuridico, n. XC, 1923, p. 166; "o legislador" prossegue "deve ter tido a intenção que o homem da lei definisse o caminho através dos conceitos não definidos e lhe aplicasse conforme aquilo que se crê como justo.”. O conceito de órgãos 


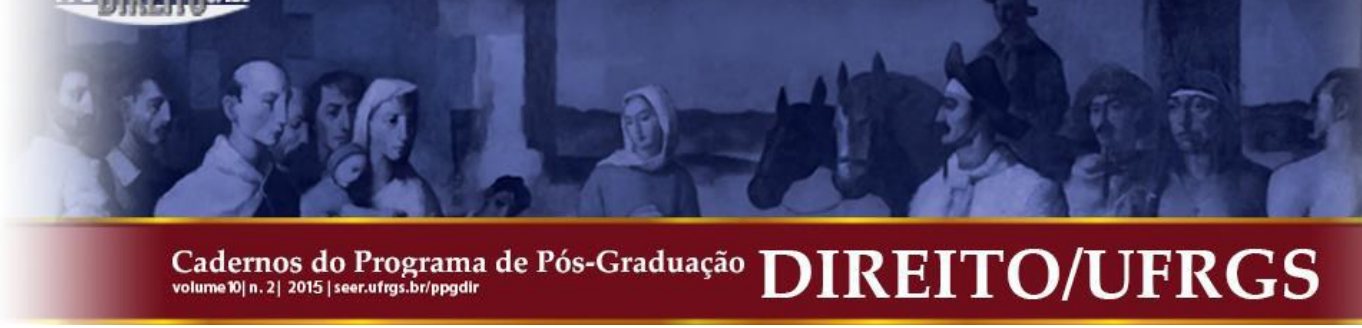

perspectivas diversas, como válvulas que colocam em comunicação o direito legal com o exterior $^{7}$; a dialética entre leis especiais e código como espaço de reorientação do direito privado no sentido solidarístico ${ }^{8}$; o abuso do direito como categoria com a qual se verifica a correspondência das faculdades exercitadas pelo titular de um direito subjetivo daquelas "necessárias para conseguir um escopo tutelado pelo direito"9.

O terreno privilegiado para o desenvolvimento destas teorias é certamente o direito civil. Todavia é importante sublinhar que - assim como do resto se pode observar para as doutrinas formalísticas - tais sensibilidades são reconduzidas a uma visão complexiva do ordenamento, tanto que dele encontramos declinações também em outros campos.

Pense-se às teses de Lodovico Mortara sobre o "método crítico" de interpretação da lei (isto é aquele método que para o jurista mantovano consiste em valorizar a função dos institutos jurídicos considerando o valor atual da norma à luz das "mutações substanciais", também onde estas não consistam em suas modificações externas ${ }^{10}$ ): tal método de interpretação é colocado em relação com uma certa concepção da divisão dos poderes que pretende ser de tipo orgânico em vez de mecânico. Aqui a recuperação das funções sistemáticas para o direito jurisprudencial corresponde a uma recuperação da função judiciária ${ }^{11}$ porque também esta, em respeito a função legislativa, em modo coordenado, mas

respiratórios foi utilizado já por outros juristas como, por exemplo, POLACCO, Vittorio. Le cabale del mondo legale. (1908). In: POLACCO, Vittorio. Opere Minori. op. cit., p. 60. Cfr. GROSSI, Paolo. Scienza giuridica italiana. Un profilo storico, 1860-1950. Milano: Giuffrè, 2000, p. 107-108.

7 Sobre as orientações manifestadas ao entorno do conceito de princípios gerais, entre outros cf. COSTA, Pietro. L'interpretazione della legge: François Gény e la scienza giuridica del Novecento. Quaderni fiorentini per la storia del pensiero giuridico moderno, n. 20, 1991, p. 429-438; GROSSI, Paolo. Scienza giuridica italiana. op. cit., p. 119-214; MECCARELLI, Massimo. Un senso moderno di legalità. Il diritto e la sua evoluzione nel pensiero di Biagio Brugi. Quaderni fiorentini per la storia del pensiero giuridico moderno, $\mathrm{n}$. 30, 2001, p. 450 et seq; SCIUMÈ, A. I principii generali del diritto nell'ordine giuridico contemporaneo (18371942). Torino: Giappichelli, 2002, passim; SOLIMANO, Stefano. Tra esegesi e sistema? Cultura giuridica e metodo scientifico di Francesco Saverio Bianchi (1827-1908). Ius. Rivista di scienze giuridiche, n. $1-2,2010$, p. 203-248.

8 Veja-se a propósito GROSSI, Paolo. Il coraggio della moderazione (specularità dell'itinerario riflessivo di Vittorio Polacco). Quaderni fiorentini per la storia del pensiero giuridico moderno, n. 18, 1989, p. 217 et seq; Id., Scienza giuridica italiana. op.cit., p. 22 et seq., e 123 et seq.; Id., L'avvio di un itinerario scientifico (una lettura del primo volume degli Scritti giuridici di Salvatore Pugliatti). Rivista di diritto civile, n. LV, 4, 2009, p. 365-384; CAZZETTA, Giovani. Responsabilità aquiliana e frammenti del diritto comune civilistico (1865-1914). Milano: Giuffrè, 1991, p. 155 et seq; Id., Scienza giuridica e trasformazioni.

9 BRUGI, B. L'abuso del diritto. op. cit., p. 81-82. Para uma consideração do problema no debate doutrinal francês veja-se CAZZETTA, Giovani. Codice civile e identità giuridica nazionale. Percorsi e appunti per una storia delle codificazioni moderne. Torino: Giappichelli, 2011, cap. VI; SABBIONETI, Marco. Democrazia sociale e diritto privato. La terza Repubblica di Raymond Saleilles (1855-1912). Milano: Giuffrè, 2011, p. 611-630.

${ }^{10}$ MORTARA, LODOVICO. Commentario. op. cit., p. VI-VIII.

11 A interpretação segue as evoluções do direito explicava Ibidem, p. VII, "através das vincendas da função judiciária, que são também as vincendas próprias da civilidade”. 


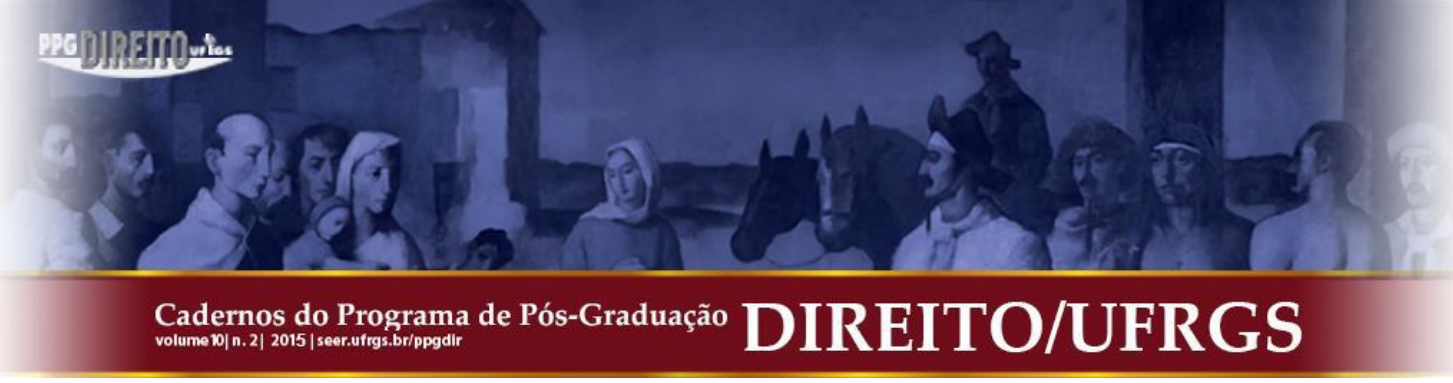

em condições de autonomia ${ }^{12}$, concorre ao exercício da soberania do estado ${ }^{13}$.

Esta ideia da Lei como "estática do direito objetivo" colocada de lado à jurisprudência "que dela constituí a dinâmica"14, implica uma margem necessariamente criativa para esta última, como foi observado, põe o juiz "ao centro da experiência"15. Mas se trata ao mesmo tempo de uma atividade concebida ainda como desenvolvimento do princípio de legalidade através da jurisdição; múltiplos corretivos sistemáticos são de fato previstos para evitar o risco de um "exaurimento da potestade legislativa"16.

Devemos necessariamente nos limitar a breves recomendações; enquanto basta para sublinhar como as estratégias discursivas sobre o método tendem a fazer com a concepção do ordenamento jurídico no seu complexo.

\section{AUTONOMIA DO DIREITO E HORIZONTE MONÍSTICO}

Voltamos em vez ao ponto da relação entre interpretação evolutiva e lei. Um similar cenário do discurso sobre a recuperação do direito jurisprudencial subtraía valor estratégico à perspectiva da redefinição do sistema das fontes do direito. Ao contrário dos muitos aspectos a recusa da equidade, ao lado da recusa do formalismo pandectístico, constituía o outro termo

12 Ibid., $\S \S 60-65$, p. 67-72 e $§ 485$, p. 591. Aquela que se atua é uma colaboração entre os poderes do Estado, para os quais o Juiz coloca em obra uma atividade que tem "o caráter de uma continuação e integração do preceito legislativo" Id., Istituzioni di ordinamento giudiziario. Firenze: Barbera, 1896, p. 23 [cursivas do autor]. Dela deriva uma "execução da vontade do legislador para tal modo especializada e integrada". [Ibid, p. 26].

13 Tratava-se de completar o processo de superação da forma de Estado despótico. A afirmação da autonomia da função legislativa constituía para Mortara somente a primeira fase da instauração da nova forma de Estado (o "Estado livre"); porque esta poderia efetivamente se configurar, precisaria também uma valorização da função judiciária nas estruturas constitucionais da soberania. Para uma reconstrução mais aprofundada se reenvia a MECCARELLI, Massimo. Giurisdizione penale e legalità in Lodovico Mortara. Quaderni fiorentini per la storia del pensiero giuridico moderno, n. 36, 2007, p. 957-979. Sobre vicenda intelectutal e biográfica de Mortara veja-se CIPRIANI, Franco. Storie di processualisti e di oligarchi: la procedura civile nel Regno d'Italia, 1866-1936. Milano: Giuffrè, 1991, passim; GIORNATA Lincea in ricordo di Lodovico Mortara, (Roma, 17 aprile 1997). Roma: Accademia nazionale dei Lincei, 1998; GROSSI, Paolo. Scienza giuridica italiana. op. cit., p. 61-66; LACCHÈ, Luigi. Personalmente contrario giuridicamente favorevole. La "sentenza Mortara" e il voto politico alle donne (25 luglio 1906). In: SBANO, N. (org.). Donne e diritti. Dalla sentenza Mortara del 1906 alla prima avvocata italiana. Bologna: Il Mulino, 2004, p. 99-151.

14 MORTARA, Lodovico. Commentario. op. cit., § 70, p. 76.

15 SATTA, Salvatore. Attualità di Lodovico Mortara (1968). Soliloqui e colloqui di un giurista. Nuoro: Ilisso, 2004, p. 400. O magistrado como viva vox legis, explica MORTARA, L. Istituzioni di ordinamento giudiziario. op. cit., p. 13-14, intervêm sob o direito escrito "adaptando-o à multiplicidade e inconstância das necessidades sociais e das ideias dominantes".

${ }^{16} \mathrm{Ibid}$, p. 30; em particular Mortara se refere a: o princípio da interpretação autêntica como prerrogativa exclusiva do poder legislativo; uma corte de cassação colocada no vértice do ordenamento judiciário, capaz de garantir a uniformidade na interpretação da lei e fugir do freio à ação integrante da jurisprudência; o vínculo aos princípios gerais contidos no direito positivo; a negação ao juiz de um poder de administração da constitucionalidade da lei. Cf. Ibidem, pp. 27-38; Id., Commentario. op. cit., v. I, §§ 87-114, p. 66-119. 


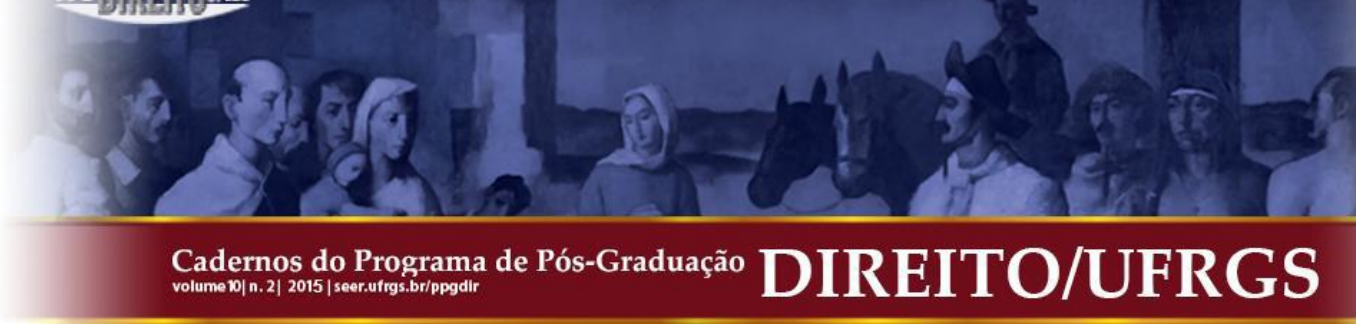

de comparação para constituir a identidade de tais abordagens metodológicas.

A abordagem da equidade deveria aparentar uma falsa abertura em respeito às expectativas de inovação do direito em sua dimensão substancial. Vê-se bem na postura prudente, diante da aceleração do Freirechtsbewegung, de personalidades como Josef Kohler e Oskar Bülow, que também tinham contribuído em modo decisivo para abrir a perspectiva do Richterrecht ${ }^{17}$. Bülow em 1906 teria precisado como o vínculo entre a jurisprudência e a lei seria irrenunciável no quadro constitucional do Estado de direito $^{18}$. Poucos anos depois Kohler teria sublinhado como o horizonte hermenêutico formalista condicionaria tanto a dimensão doutrinal quanto aquela judicial. O problema anterior que das fontes aparentava ser de método: precisava construir uma diversa interação entre a lei, ciência jurídica e juiz, para uma efetiva superação do horizonte formalístico em modo de construir o direito "durch das zusammenwirken von Gesetz, Wissenschaft und Richterspruch" ${ }^{19}$; também no novo horizonte hermenêutico já haveria precisado em 1886, "soll immer die Jurisprudenz noch wissenschaftliche Jurisprudenz bleiben" 20 .

Tal dificuldade para aceitar a equidade como fonte de direito se encontrava também na ciência jurídica italiana ${ }^{21}$. Pensem-se nas teses de Biagio Brugi.

Para o jurista pisano o caráter legicêntrico do ordenamento é irrenunciável se não se quer colocar em risco sua força complexiva ${ }^{22}$. O juiz é chamado a dar um aporte específico,

\footnotetext{
${ }^{17}$ Nos referimos ao ensaio de KOHLER, Josef. Über die Interpretation von Gesetzen. Zeitschrift für privat- und öffentliche Recht der Gegenwart, n. XIII, 1886, p. 1-61 e a BÜLOW, Oskar. Gesetz und Richteramt. Leipzig: Duncker und Humblot, 1885. Cfr. OGOREK, Regina. Richterkönig oder Subsumtionsautomat? Zur Justiztheorie in 19. Jahrhundert. Frankfurt am Main: Klostermann, 1986, p. 158 et seq.; HENNE, Thomas; CARSTEN, Kretschmann. Ein Mythos der Richterrechtsdiskussion: Oskar Bülow, Gesetz und Richteramt. Ius commune, Frankfurt am Main, n. 26, 1999.

${ }^{18}$ BÜLOW, Oskar. Über das Verhältnis der Rechtsprechung zum Gesetzesrecht. Das Recht, n. X, 1906 , coll. 770-780. Cf. OGOREK, Regina. Richterkönig. op. cit., p. 269 et seq; HENNE, Thomas; CARSTEN, Kretschmann. Ein Mythos. op. cit., p. 223 et seq.

19 KOHLER, Josef. Ein "juristischer Kulturkampf! Archiv für Rechts- und Wirtschaftsphilosophie, n. VI, 1912-1913, p. 275-281; a citação é na página 278.

20 Id., Über die Interpretation von Gesetzen. op.cit., p. 57.

${ }^{21} \mathrm{O}$ evidenciaram os estudos de COSTA, P. L'interpretazione della legge. op. cit., p. 398 et seq.; GROSSI, Paolo, Scienza giuridica italiana. op. cit., p. 102-108; LATINI, Carlotta. L'araba fenice. Specialità delle giurisdizioni ed equità giudiziale nella riflessione dottrinale italiana tra Otto e Novecento. Quaderni fiorentini per la storia del pensiero giuridico moderno, n. 35, 2006, p. 595-657; SOLIMANO, Stefano. Tra esegesi e sistema? op. cit., p. 217-228.

${ }^{22}$ É um ponto de vista constante em seus escritos. Veja-se, por exemplo: BRUGI, B. Senso giuridico romano e senso moderno di legalità. Atti del Real Istituto veneto di scienze lettere ed arti, n. LIX, Parte II, 1900, p. 430-432; Id., Logica di leggi e logica di scienza. Rivista italiana di sociologia, n. V, 1901, p. 168; Id., Nel regno della filosofia del diritto. Padova: Tipografia Randi, 1905, p. 63-67; Id., Della proprietà. op. cit., v. I, p. VII-VIII; Id., L'equità e il diritto positivo. Rivista internazionale di filosofia del diritto, n. III, 1923, p.
} 


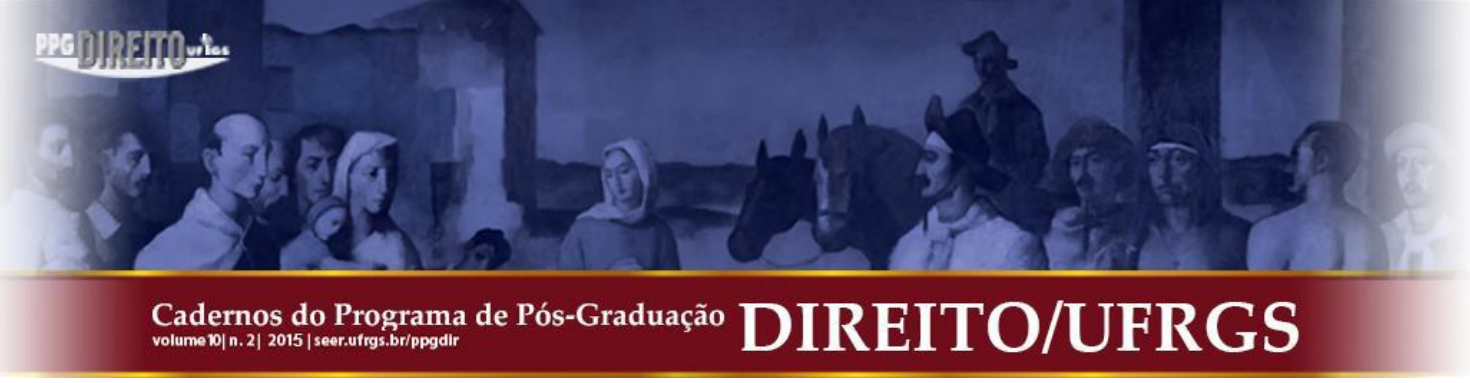

mas a partir das escolhas operadas pelo legislador, fazendo-se executor da sua obra ${ }^{23}$ e permanecendo um jurista ${ }^{24}$. Afinal os instrumentos da interpretação evolutiva da lei, observava Brugi, já implicam um papel de primeiro escalão para o juiz. Isto vale para as cláusulas gerais onde a individualização do sentido dos conceitos indeterminados depende essencialmente de um arbitrium boni viri ${ }^{25}$; discurso similar é feito para a dialética entre leis especiais e códigos. Sobre tal terreno o juiz é chamado a desenvolver um insubstituível papel de composição dos interesses tutelados pelas diversas normas de lei ${ }^{26}$; o emprego da categoria do abuso de direito, do seu lado, implica necessariamente uma ponderação entre contrastantes interesses de exclusiva pertença do juiz ${ }^{27}$; depois há todo o campo dos princípios gerais, no qual, na opinião de Brugi, é, sobretudo, o juiz que deverá prosseguir a obra de tradução do potencial historicístico do ordenamento, que a legislação tem somente em parte realizado ${ }^{28}$.

O problema em suma não parece ser reconhecer um espaço criativo à jurisprudência, mas o fato de substituir um primado, o primado da lei, com um outro primado, o primado da equidade do juiz. Se o verdadeiro primado a ser afirmado é aquele do jurista intérprete, é no topo de sua atividade hermenêutica, que vão se concentrar as dinâmicas de renegociação da relação entre direito e realidade.

Mas isto significa renunciar a perseguir o objetivo da inovação sob o terreno das fontes do direito e reconduzir o problema sob o terreno de um confronto entre o intérprete e lei.

Tentamos trazer uma primeira conclusão; as posições teóricas que temos considerado mostram um traço comum: mesmo nas suas diferentes construções tendem

452.

${ }^{23}$ Id., Della proprietà. op. cit., v. I, p. 161; Id., Di un fondamento filosófico. op. cit., p. 8. Outro exemplo é aquele de MORTARA, L. Istituzioni di ordinamento giudiziario. op. cit., p. 13 et seq.

${ }^{24}$ BRUGI,B. Introduzione enciclopedica alle scienze giuridiche e sociali. Firenze: Barbera, 1891, p. 248.

${ }^{25}$ Id., Della proprietà. op. cit., v. I, p. 175-177. Cf. RAGGI, Luigi. Appunti sull'interpretazione progressiva. Rivista internazionale di filosofia del diritto, n. III, 1923, pp. 336-339.

${ }^{26}$ BRUGI, B. Della proprietà. op. cit., v. I, p. 172.

${ }^{27}$ Id., L'abuso del diritto. op. cit., p. 81-82.

${ }^{28}$ Id., Introduzione enciclopédica. op. cit., p. 31; Id., I principi generali del diritto. op. cit., p. 160-166; Id., L'analogia di diritto e il cosiddetto giudice legislatore. Il diritto commerciale, n. 35, 1916, p. 263-270. Sobre esta tese de Brugi também em relação ao vivaz debate doutrinal no qual se inseriam reenviamos a COSTA, P. L’interpretazione della legge. op. cit., p. 426 et seq; MECCARELLI, Massimo. Un senso moderno di legalità. op. cit., p. 450 et seq. Sobre os itinerários teóricos de Biagio Brugi, vejam-se também MARINO, Giovanni. Positivismo e giurisprudenza. Biagio Brugi e la congiunzione di scuola storica e filosofia positiva. Napoli: ESI, 1987; Id., Biagio Brugi e il "metodo storico" nella determinazione dei principi del diritto. Index, n. 16, 1988, p. 299-325; GROSSI, P. La scienza del diritto privato. op. cit., p. 178-184; Id., Scienza giuridica italiana. op. cit., p. 140-146; LATINI, Carlotta. L'araba fenice. op. cit., p. 609-657. 


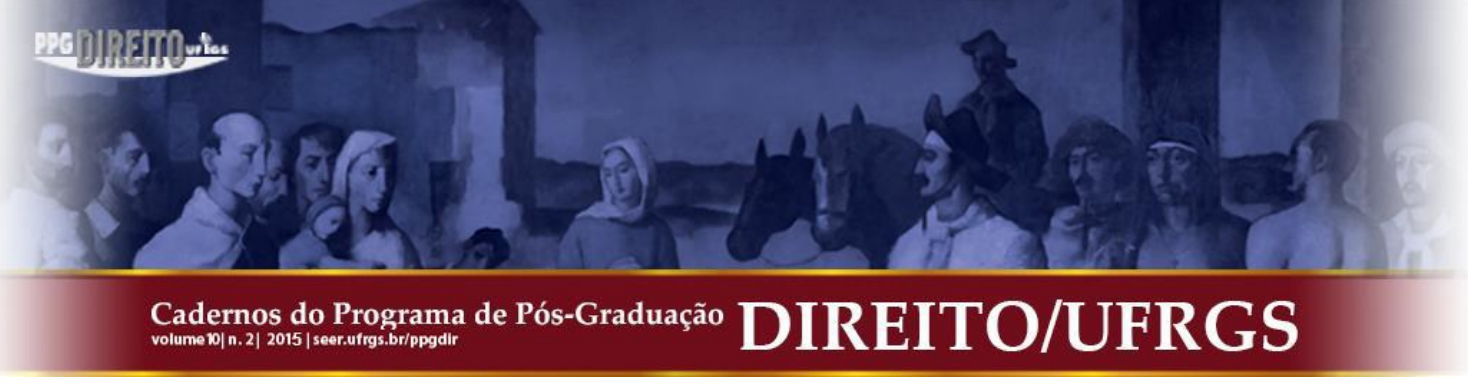

a se fundar todas sob uma concepção monística do fenômeno jurídico ${ }^{29}$, seja no sentido de reconduzir os processos de sua manifestação a um único fundamental princípio ordenante; seja no sentido de compor eventuais tensões dialéticas nas expressões de pluralismo, através de uma confirmação do único princípio fundamental ordenante.

O potencial inovativo de algumas teorias sobre interpretação evolutiva e a conexa recuperação do direito jurisprudencial aparecem desenvolvidas em uma, embora original, perspectiva legalística.

É um discurso que vale, na minha opinião, também para aquelas orientações inovativas que superam o horizonte das interpretações da lei, acolhendo a ideia de um direito além da lei, direta expressão da sociedade. Também em tais casos, de fato, a abertura pluralística sob o plano sistemático, parece coexistir sob o fenomenológico com uma concepção monística: a redefinição do sistema das fontes do direito corresponde a uma doutrina que tende a negar uma justaposição entre as mesmas (por exemplo estabelecendo uma ordem hierárquica e, contudo, protegendo a lei da erosão da jurisprudência).

Aquilo, como foi demonstrado ${ }^{30}$, é relevável em François Gény ${ }^{31}$, mas é bem evidente também no heterogêneo panorama italiano entre os juristas que dividem as hipóteses de uma abertura do sistema das fontes para além da lei, embora segundo orientações e com finalidades muito diversas entre si. Pense-se por exemplo de Alberto Asquini onde o reconhecimento da natureza dos fatos como fonte do direito serve para reiterar a "teoria positiva sobre princípios gerais" 32 . Pense-se também em Vincenzo Miceli que, enquanto reconhece o espaço da equidade, também opta por uma concepção

\footnotetext{
${ }^{29}$ Sobre o monismo jurídico como horizonte pré-compreensivo vejam-se as observações de GROSSI, P. L'Europa del diritto.Uno storico del diritto in colloquio con gli storici del pensiero economico. Il pensiero economico italiano, XVI, 2008, p. 16 et seq.; ZAGREBELSKY, Gustavo. La legge e la sua giustizia. Bologna: il Mulino, 2008, p. 250 et seq.; OST, François; VAN DE KERCHOVE, Michel. De la pyramide au réseau? Pour une théorie dialectique du droit. Bruxelles: Facultés universitaires Sant-Louis, 2002, p. 450 et seq.

${ }^{30}$ Veja-se a propósito GROSSI, Paolo. Ripensare Gény. Quaderni fiorentini per la storia del pensiero giuridico moderno, n. 20, 1991, p. 29-36; COSTA, P. L'interpretazione della legge. op. cit., p. 375 et. seq.; SABBIONETI, Marco. Democrazia sociale e diritto privato. op. cit., p. 325-329. Significativo é relevar também BÜLOW, O. Über das Verhältnis. op. cit., coll. 773-774, teria distinguido as posições de Gény daquelas de Ehrlich, Rumpf e Stampe, mesmo sob o ponto do reconhecimento do princípio da Verbindlichkeit des Gesetzesrechts.

${ }^{31}$ GÉNY, François. Méthode d'interpretation et sources en droit privé positif. 2. ed. v. I. Paris: LGDJ, 1919, p. 316-446, em particular p. 383-387.

${ }^{32}$ ASQUINI, A. La natura dei fatti come fonte del diritto (1921). In: ASQUINI, A. Scritti giuridici. Padova: Cedam, 1936, p. 19-20.
} 


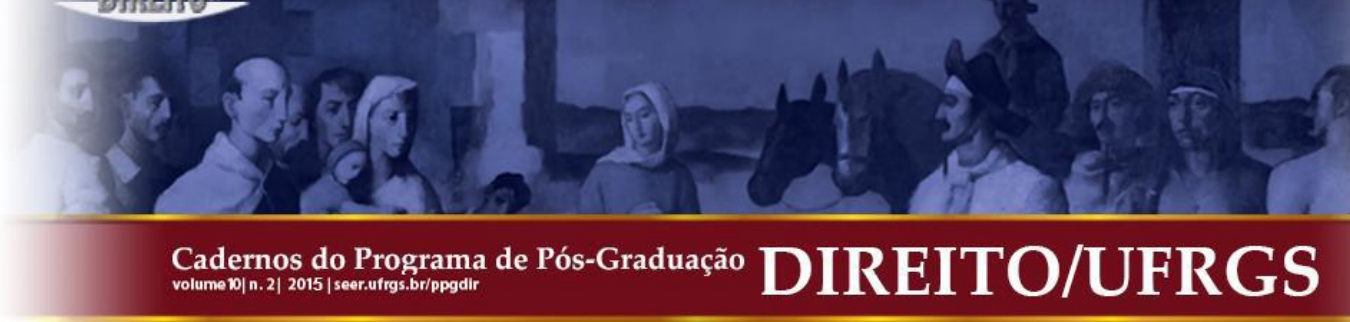

positivística dos princípios gerais do ordenamento ${ }^{33}$. Significativa é também a atitude dos irmãos Nicola e Leonardo Coviello os quais, enquanto solicitavam ao legislador a abertura no terreno da equidade do juiz, refutam a perspectiva da interpretação evolutiva porque "pisa" na $1 \mathrm{ei}^{34}$.

Discurso diverso parece poder ser feito somente para a Freirechtsbewegung. Aqui a abertura ao pluralismo de fontes, é associada a um perfil que se reflete de modo decisivo sobre a natureza do direito jurisprudencial; esta de fato parece pensada também para fazer emergir campos de tensão no processo de manifestação do direito, como momentos fisiológicos de geração do ordenamento jurídico.

Em um certo sentido se poderia dizer que é sobretudo da sua irredutibilidade que depende o nível de vedação entre direito e realidade e a possibilidade que o direito jurisprudencial se faça fiel intérprete das exigências sociais.

Bastariam aqui três rápidos exemplos. Na concepção da relação juiz-lei em Hermann Kantotowicz a freie Rechtschöpfung em efeito vêm afirmada não simplesmente nos termos (monísticos) de um mero primado da equidade: ela é resultante sobretudo de uma dialética entre as escolhas do legislador e a escolha do juiz no quadro de uma função comum, aquela da Rechtspflege, que vem desenvolvida em recíproca condição de autonomia ${ }^{35}$. Também Ernst Stampe descreve a função do juiz

\footnotetext{
${ }^{33}$ MICELI, Vincenzo. Sul principio di equità. In: Studi di diritto romano, di diritto moderno e di storia del diritto pubblicati in onore di Vittorio Scialoja nel XXV anniversario del suo insegnamento. v. II. Milano: Hoelpi, 1905, p. 89; Id. I principi generali del diritto. Rivista di diritto civile, n. XV, 1923, p. 35-42.

${ }^{34}$ COVIELLO, Nicola. Manuale di diritto civile. op. cit., p. 88-92: “o método evolutivo em seguida é aquele que mais dos outros se cobre de hipocrisia, porque enquanto propõe o respeito da lei, a pisa; daí que reduz a lei a uma moldura na qual qualquer quadro pode se fazer entrar, a uma fórmula algébrica, na qual às letras possam se fazer corresponder os números que se queiram, a uma aparência destituída de substância! " [p. 92]. Veja-se também: CoviELlo, Dei moderni metodi. op. cit., p. 37-39. Linha similar é aquela retraçável na crítica de Gény à méthode historique e à teoria da assouplissement-, cfr. SABBIONETI, Marco. Democrazia sociale e diritto privato. op. cit., p. 326.
}

${ }^{35}$ KANTOROWICZ, Hermann. Der Kampf um die Rechtswissenschaft (1906). In: KANTOROWICZ, Hermann. Rechtswissenschaft und Soziologie. Ausgewählte Schriften zur Wissenschaftslehre. Karlsruhe: Muller, 1962, p. 33 et seq. É um conceito que Kantorowicz reitera também em outros escritos aí colhidos como exemplo Aus der Vorgeschichte der Freirechtslehre, (1925), p. 43 et seq.; Staatsauffassungen, (1925), p. 71-72; Die Rechtswissenschaft — eine kurze Zusammenfassung ihrer Methodologie, (1928), p. 89 et seq.; Rechtswissenschaft und Soziologie, (1911), p. 126 et seq.

Sobre as orientações de Kantorowicz e Ehrlich como de outras figuras da Freirechtshewegung vejam, entre outros, FEBBRAJO, Alberto. Eugen Ehrlich: dal diritto libero al diritto vivente. Sociologia del diritto, 1982, p. 137-159; MUSCHELER, Karlheinz. Relativismus und Freirecht. Ein Versuch über Hermann Kantorowicz. Heidelberg: Müller, 1984; REHBINDER, Manfred. Die Begründung der Rechtssoziologie durch Eugen Ehrlich. Berlin: Duncker \& Humblot, 1986; SCHRÖDER, Jan. Gesetzesauslegung und Gesetzesumgehung. Das Umgehungsgeschäft in der rechtswissenschaftlichen Doktrin von der Spätaufklärung bis zum Nationalsozialismus. Paderborn, München, Wien, Zürich: Schöningh, 1985, p. 93 et seq.; SCHRÖDER, Rainer. Die deutsche Methodendiskussion um die Jahrhundertwende: Wissenschafts- theoretische 


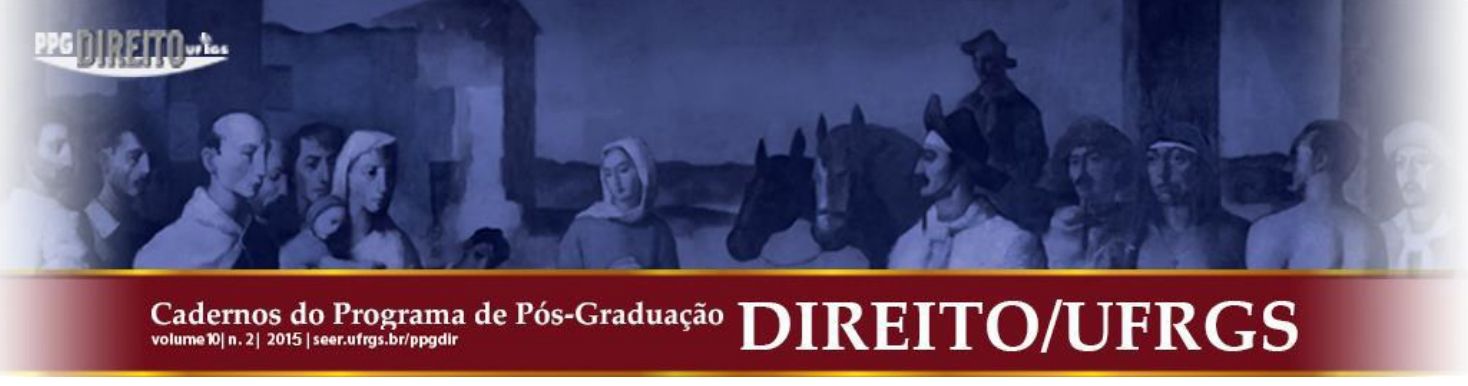

como uma selbständige Rechtschöpfung, a atividade de criação do direito praeter e contra legem, além disso, é relevante também com relação ao problema do nicht verfassungsmässig ausgeprochenen Gesetzeswillen ${ }^{36}$. Observando a Eugen Ehrlich, ao fim, se pode observar como na superação do horizonte da Gesetzesanwendung, imposto pela procura da Gerechtigkeit e na correlativa distinção entre technische Rechtsfindung e freie Rechtsfindung, um papel decisivo reveste a ideia de uma certa extratextualidade do direito, que fixa, como dimensão jurídica coexistente e não hierarquicamente subordinável, o direito legislativo estatal e que somente o juiz como pessoa (e não o Estado com as suas leis) pode colher ${ }^{37}$.

Trata-se de teses de forte impacto sob o plano sistemático. Estas posteriormente, além de tocar o tema das fontes, empurram-se também sobre o específico terreno da refundação metodológica da própria ciência jurídica, no sentido de uma inversão de tendência a respeito das consolidadas abordagens hermenêuticas formalísticas.

Todavia, como é notório, a incidência da Freirechtsbewegung foi muito inferior ao seu potencial inovativo. Trata-se de uma orientação emergida quando talvez a opção legalística tinha celebrado na Alemanha o seu definitivo triunfo com a emancipação do BGB; o jusliberalismo, também por causa do dramático grampo que a história alemã teria conhecido após a falência da experiência Weimeriana, não teria margem suficiente para traduzir-se em um projeto efetivamente capaz de deteriorar a sólida ancoragem legalística da cultura jurídica.

O paradigma da legalidade, com a concepção monística que teria implicado, embora com declinações diversas, parece ter circunscrito o horizonte de referência para a generalidade da ciência jurídica continental entre os Oitocentos e os Novecentos.

Präzisierungsversuche oder Antworten auf den Funktionswandel von Recht und Justiz. Rechtstheorie, n. 19, 1988 , p. 345 et seq.; VOGL, Stefan. Soziale Gesetzgebungs- politikfreie Rechtsfindung und soziologische Rechtswissenschaft bei Eugen Ehrlich. Baden-Baden: Nomos, 2003; SILBERG, Sebastian. Hermann Kantorowicz und die Freirechtsbewegung. Berlin: Logos, 2004; BEATSON, J. ZIMMERMANN R. (Eds.). Jurists uprooted. German-speaking émigré lawyers in Twentieth-century Britain. Oxford: Oxford University Press, 2004; HERTOGH, Marc. (Org.). Living law: reconsidering Eugen Ehrlich. Oxford, Portland (OR): Hart, 2009.

${ }^{36}$ STAMPE, ERnST. Die Freirechtsbewegung. Gründe und Grenzen ihrer Berechtigung, Berlin: Franz Wahlen, 1911, em particular p. 25 et seq. Cf. infra, parágrafo conclusivo.

${ }^{37}$ EHRLICH, Eugen. Freie Rechtsfindung und freie Rechtswissenschaft. Leipzig: Hirschfeld, 1903, em particular p. 18 et seq. De Ehrlich vejam-se também: Soziologie und Jurisprudenz (1906). In: EHRLICH, Eugen. Gesetz und lebendes Recht. Vermischte kleinere Schriften. Berlin: Duncker \& Humblot, 1986, p. 88103 e Ibid.Die Neuordnung der Gerichtsverfassung, (1907), p. 146-178. 


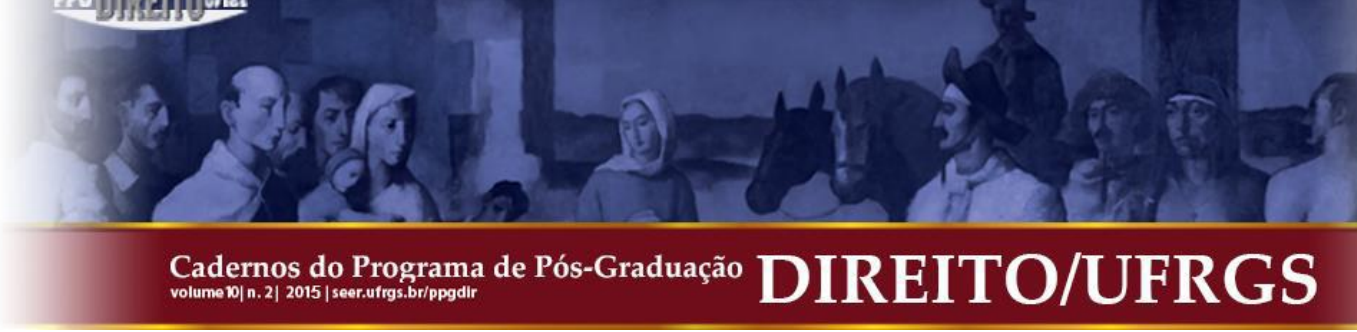

\section{A JURISPRUDÊNCIA DAS CORTES SUPREMAS COMO FATOR DE ESTABILIZAÇÃO: UMA COMPARAÇÃO ENTRE FRANÇA, ALEMANHA E ITÁLIA}

Direcionaremos agora a nossa atenção sobre as características da jurisdição. Também aqui aparenta evidente como a recuperação do direito jurisprudencial restou concebida dentro do horizonte legalístico. Consideramos a respeito à experiência maturada em três contextos estatais diferentes, a francesa, a alemã e a italiana, concentrando-se na característica fundamental da função e das características da jurisdição suprema.

Durante a Revolução francesa, de fato, mesmo ao nível de jurisdição suprema se entendia obter a neutralização do direito jurisprudencial diante da lei. Com a introdução da cassação no ordenamento processual e judiciário de fato se intervinha sob a dinâmica concreta de desenvolvimento da jurisprudência, não somente para controlá-la, mas também para desnaturá-la.

A cassation introduzia duas novidades que interessavam diretamente aos regimes do direito jurisprudencial: a primeira consistiria em dar relevância a uma inédita separação entre questões de fato e questões de direito. De modo que o juízo do juiz supremo se restringisse somente a esta última; a cassação, dizia-se, não é chamada a sancionar as decisões injustas; é prevista somente para sancionar a violação da lei.

A segunda novidade consistia em transformar o juízo diante do juiz supremo em um espaço procedimental de êxito meramente rescindente, o juiz supremo - cada vez que tivesse ocorrido uma violação da lei - era obrigado a enviar a sentença ao juiz de mérito para a decisão.

Sem entrar em demasia nos detalhes técnicos, basta aqui recordar que a ideia guia era a de tutelar a vontade do legislador, transformando o terceiro grau de juízo ( $d e$ iure litigatoris) em um momento de verificação da correta aplicação da lei (de iure constitutionis), esta serviria para anular o julgado, não para construí-lo. Empregava-se uma atividade jurisprudencial em sentido antijurisprudencial no interesse da lei. Em tal modo a jurisprudência não teria conseguido mais se colocar em contraste com as escolhas do legislador, nem teria conseguido se desenvolver segundo dinâmicas 


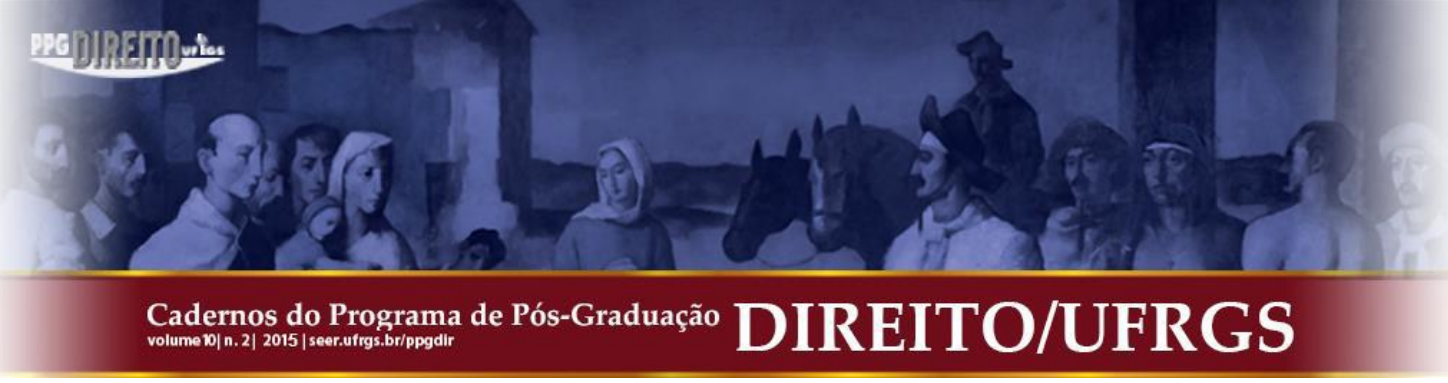

autônomas daquelas escolhas. Com a cassation se entendia traduzir em concreto uma concepção mecanicista da aplicação da lei.

A realização de tal programa de lineamentos suficientemente simples seria complicada sensivelmente no curso dos "oitocentos", abrindo-se a uma significativa recuperação de espaço para o direito jurisprudencial.

Servindo-se dos restritivos cenários originários, a Cour de cassation, instituída no $28^{\circ}$ floreal do ano XII em substituição do Tribunal de cassation assumiu um papel de primeiro plano no desenvolvimento do direito jurisprudencial ${ }^{38}$. Parte não secundária encontrou nisso uma progressiva tendência para estender o campo dos motivos de recurso na Cassação, de modo que à figura da contravenção expressa da lei são arroladas também aquelas da fausse application (uma contravention négative) do défaut de base légale e do defeito de motivação da sentença ${ }^{39}$. Decisiva foi em seguida a introdução, em 1837, do juízo de Chambres réunies sobre um segundo recurso pelos mesmos motivos, naquele caso a sentença de reenvio da Cassação assumia um valor vinculante, quanto às questões de direito, para o juiz de mérito.

Com tais atribuições a Cour de cassation ficou em grau de produzir orientações interpretativas e promover a uniformidade da jurisprudência ${ }^{40}$.

\footnotetext{
${ }^{38}$ Veja-se neste ponto MONTAZEL, Laurence. Entre fait et droit: histoire d'un pouvoir judiciaire. Les techniques de la cassation civile en France et en Allemagne au XlXème siècle. Frankfurt am Main: Klostermann, 1998, p. 1-89; MECCARELLI, Massimo. Le Corti di cassazione nell'Italia unita. Profili sistematici e costituzionali della giurisdizione in una prospettiva comparata. Milano: Giuffrè, 2005, p. 127135 e 176-182; Id., Cassation, révision et tâche de la juridiction: une comparaison entre France, Allemagne et Italie au cours du XIXe siècle. In: HAUTEBERT, J.; SOLEIL, S. (orgs.). Modèles français, enjeux politiques et élaboration des grandes textes de procédure en Europe. Paris: Editions juridiques et techniques, 2007, p. 153-157. Uma tendência à reconstrução de um papel guia no desenvolvimento da jurisprudência é, contudo, já encontrável na experiência do próprio Tribunal de cassation-, a respeito HALPERIN, Jean-Louis. Le Tribunal de cassation et les pouvoirs sous la Révolution (1790-1799). Paris: LGDJ, 1987, passim e em particular p. 267-269. Com respeito à cassation vejam CALAMANDREI, Piero. La cassazione civile. I, Storia e legislazioni (1920). In: CALAMANDREI, Piero. Opere giuridiche. v. VI. Napoli, Morano, 1976; ROYER, Jean-Pierre. Histoire de la justice en France de la monarchie absolue à la République. Paris: PUF, 1995; GLAESER, Mathias. Lehre und Rechtsprechung im französischen Zivilrecht des 19. Jahrhunderts. Frankfurt am Main: Klostermann, 1996; ALVAZZI DEL FRATE, P. Giurisprudenza e référé législatif in Francia nel periodo rivoluzionario e napoleonico. Torino: Giappichelli, 2005.

${ }^{39}$ Veja-se, por exemplo: BONCENNE, Pierre. Théorie de la procédure civile. Paris: Videcoq, 1837, p. 501548; CRÉPON, Théophile. Du pourvoi en cassation en matière civile. v. I. Paris: Larose \& Forcel, 1892, p. 217-222, e v. III, p. 3-6 e 47-48, 95-129; FAYE, Ernest. La Cour de cassation. Paris, 1903 (ristampa, Paris, Auvermann, 1970), p. 127-135,186-196, 312-319; DE LA GRASSERIE, Raoul. De la fonction et des juridictions de cassation en législation comparée (évolution, comparaison critique, réforme). Paris: LGDJ, 1911, p. 17 e 45-49.

${ }^{40}$ MARTY, Gabriel. La distinction du fait e du droit. Essai sur le pouvoir et le contrôle de la Cour de cassation sur les juges du fait. Paris: Sirey, 1929, p. 206 et seq.; SALOMÉ, Yvonne. Les pouvoirs de contrôle de la Cour de cassation en matière de conflits des lois. Paris, Sirey, 1938, p. 17 et seq. Constatavam-no também GÉNY, F. Méthode d'interprétation. op. cit., p. 90-96 e EHRLICH, E. Freie Rechtsfindung. op. cit., p. 26.
} 


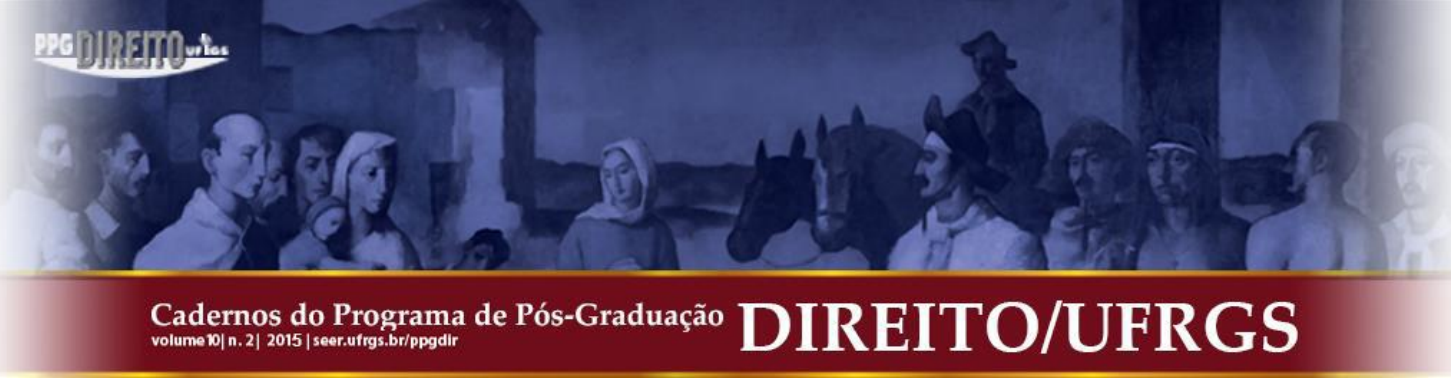

Reichsgericht ${ }^{43}$ - que, dividida em seções competentes por território, teria operado sob diversos ordenamentos regionais, para promover uma Rechtsharmonisierung e favorecer a emersão de um direito nacional: construir uma jurisprudência unitária, dizia-se ${ }^{44}$, para obter um direito unitário.

O instrumento processual de uma tal jurisdição suprema, também aqui limitamos ao mínimo as precisões técnicas, não teria conseguido ser aquela da cassação, escolheu se de fato aquela da revisio in iure: um juízo de terceiro grau limitado a um reexame da questão de direito, mas, aplicando a questão de direito ao fato, seria capaz de produzir sentenças com efeitos rescisórios.

Também em tal esquema os motivos do recurso de terceiro grau vinham reduzidos às hipóteses da violação de lei; todavia, na falta de um código e na presença de sistemas jurídicos diferentes entre si, esta vinha considerada em sentido amplo como referida ao "direito material" (compreendendo também o consetudinário) ${ }^{45}$. Isto teria consentido ao Reichsgericht de operar sobre terrenos que, ao invés, no sistema francês, eram interditos à Corte de cassação ${ }^{46}$. Correlativamente a separação entre questões de

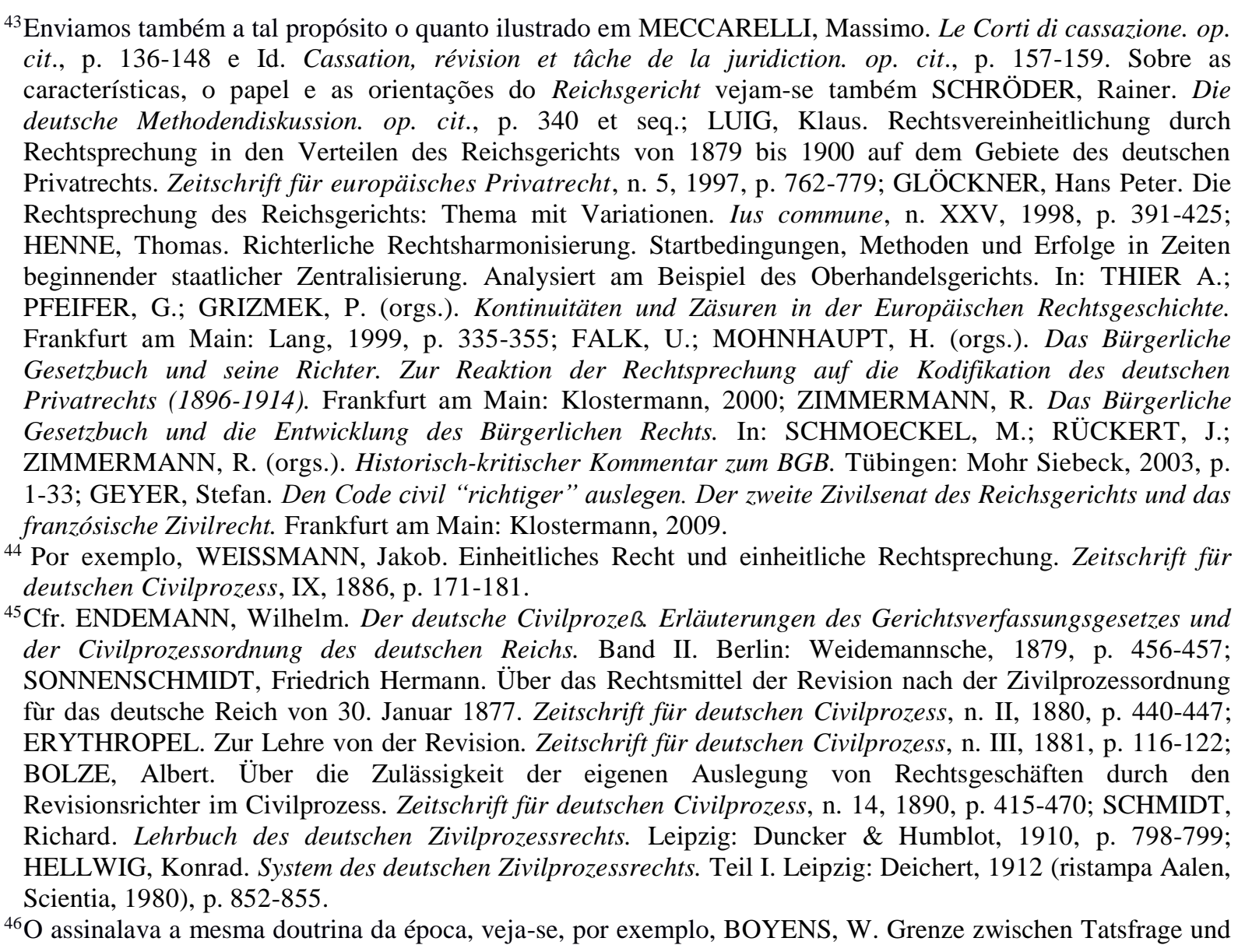
Cadernos do Programa de Pós-Graduação em Direito PPGDir./UFRgS | Edição Digital | Porto Alegre | Volume X | Número 2 | 2015 | P.4-37 


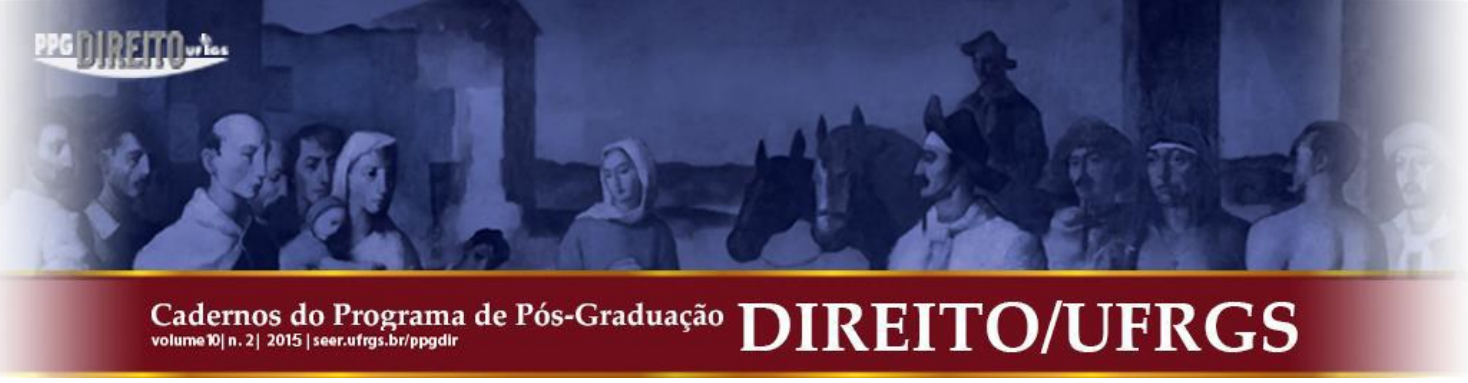

fato e de direito era pensada, sobretudo, para fazer com que o juiz de terceiro grau se colocasse a questão da justiça substancial somente como questão de direito (ao contrário, na França, servia a distinguir entre controle da decisão que violava a lei e controle da decisão injusta).

Para tais suas peculiaridades o Reichsgericht se tornava idôneo para exercitar uma atividade jurisprudencial criativa, mas a sua Rechtsfortbildung não se colocava necessariamente em termos de incompatibilidade com um horizonte de direito codificado, e, sobretudo, com o projeto edificatório da pandectística.

Se é verdade que da Alemanha do século XIX nos vem proposto um tipo de direito jurisprudencial diferente daquele contemporaneamente emergente do arranjo institucional francês, é também verdade que este, por constituir para certos aspectos também uma manifestação de autonomia do direito, parece se colocar no interior do processo de modernização que se está cumprindo, no sinal da redução do direito na lei.

Observamos agora um terceiro cenário, o italiano. Também aqui temos uma tardia unificação territorial nacional, para um território no qual são consolidadas nos séculos diversas tradições jurídicas. Ao novo Estado unificado, porém se quis dar rapidamente um direito nacional, renunciando a pavimentar um diverso percurso de ponderação do direito unitário ${ }^{47}$. Isto conferiu um perfil de inadequação originário ao direito codificado italiano (acentuando-se em seguida com as transformações econômico-sociais do final dos Oitocentos) e propriamente para isto ele não estaria em grau de desenvolver, por si só, uma função conformativa, seria um pouco destinado a depender do momento hermenêutico.

Tal quadro influenciou certamente as características assumidas pela jurisdição suprema. Em 1865, com o código de processo civil, vem definitivamente escolhido um sistema de cassação, segundo as regras consolidadas na França, orientado ao controle da violação de lei, com mero poder rescisório. Todavia se tratava de uma originalíssima hibridização da ideia de cassation.

Basta aqui acenar a dois perfis somente: na Itália operam até os 1923 não uma, mas cinco cortes supremas de cassação civil, elas exercitaram a própria jurisdição e

Rechtsfrage in den Zivilsenaten des Reichsgerichts. Die ersten 25 Jahre des Reichsgerichts. Leipzig: Roßberg, 1904, p. 155.

${ }^{47}$ SOLIMANO, Stefano. "Il letto di Procuste". Diritto e politica nella formazione del codice civile unitario. I progetti Cassinis, (1860-1861). Milano: Giuffrè, 2003; Id., L’edificazione del diritto privato italiano: dalla restaurazione all'Unità. Forum Historiae Iuris, 17. Mai 2005, disponível em: http://www.forhistiur.de. 


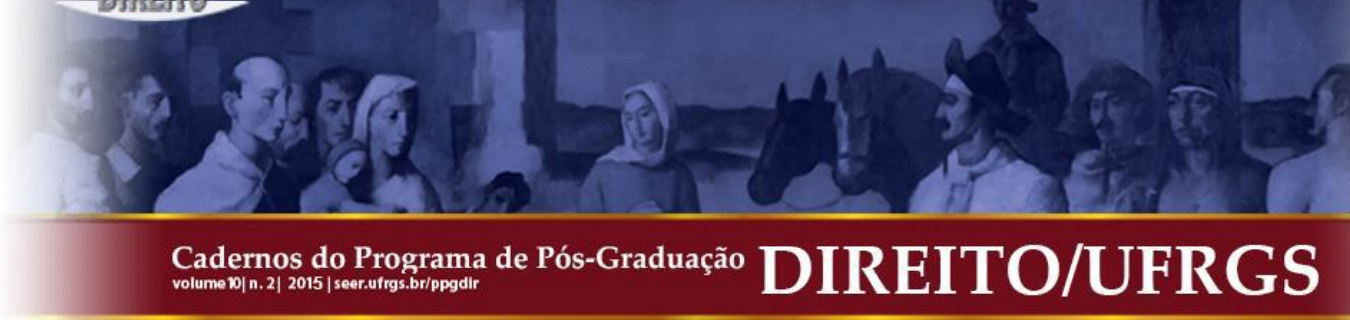

desenvolveram a própria jurisprudência sob territórios distintos e em modo autônomo entre si. Além do elenco dos motivos de recurso previsto, pelo código de processo civil de 1865 resultava mais amplo em relação ao que caracterizava o ordenamento francês, isto permitia à cassação italiana a passar dos limites sobre a questão de fato mesmo conservando o princípio da separação entre a questão de direito e de fato ${ }^{48}$. A cassação italiana, com tais seus tratos peculiares, se aproximava em tal modo à Revision alemã sem, porém, receber dela um traço decisivo: a possibilidade de aplicar ao fato a questão de direito.

Tal original emprego do instituto da cassação conseguiu favorecer na Itália a instauração de uma relação dialética entre direito codificado e jurisprudência, seja no sentido de dar daquele momento judicial o valor de uma ponderação de direito positivo a respeito das exigências de justiça, seja no sentido de aumentar a capacidade de penetração hermenêutica do direito positivo, para favorecer dela a necessária evolução e determinar as necessárias pontes de síntese ${ }^{49}$.

Ao mesmo tempo, porém, tal direito jurisprudencial foi produzido por uma jurisdição suprema que se interpôs entre o direito codificado e a jurisprudência

\footnotetext{
${ }^{48}$ As cortes de cassação no Reino da Itália tinham sede em Torino, Firenze, Napoli, Palermo e (no 1875) Roma. Sua autonomia recíproca foi corregida a partir de 1888; com a lei que unificava as cassações penais, de fato, dispõe-se também a concentração da competência para os recursos das seções unidas tão somente na Cassação de Roma. Para maiores aprofundamentos enviamos a MECCARELLI, Massimo. Le Corti di cassazione. op. cit., passim. Sobre as Cassações italianas vejam também La cassazione civile. op. cit., p. 669 et seq.; TARUFFO, Michele. Cassazione e revisione: un problema nella storia delle istituzioni giudiziarie. $I l$ vertice ambiguo. Bologna: il Mulino, 1991, p. 27-50; SCIUMÈ, A. Fra revisione e cassazione: modelli di organizzazione giudiziaria e politica dell'unificazione nella Lombardia postunitaria. lus mediolani. Studi di storia del diritto milanese offerti dagli allievi a Giulio Vismara. Milano: Giuffrè, 1996, p. 979-1050; CIPRIANI, Franco. La scomparsa di Carlo Lessona e La cassazione di Piero Calamandrei. Il giusto processo civile, 1, 2008, p. 3-40.

${ }^{49} \mathrm{Cf}$. BORSARI, Luigi. Il codice italiano di procedura civile annotato. Parte I. Roma, Napoli: UTET, 1872, p. 649 et seq.; MARCHETTI, Raffaele. Terza istanza e cassazione. Relazioni e deliberazioni del Circolo legale romano sulle tesi proposte al primo Congresso giuridico italiano. Roma: Mugnoz, 1872, p. 179 et seq.; BRUSA, E. Dell'unità di Cassazione penale. Annuario delle scienze giuridiche sociali e politiche, n. 4, 1883, p. 276-277; SANGIORGI, Antonino. Relazione della Commissione istituita per studiare un Progetto di costituzione della suprema magistratura del Regno. Il circolo giuridico, v. XXII, 1891, p. 290 et seq.; ORLANDO, Vittorio Emanuele. Sull'unificazione della Cassazione civile. Palermo: F.lli Vena, 1893, p. 813; MoRTARA, L.Commentario. op. cit., §§61-75, p. 67-81; ZANARDELLI, G. Relazione al disegno di legge sull'ordinamento giudiziario. Atti della Camera dei Deputati. Documenti, Legislatura XXI, 2a Sessione 1902-1903, Roma, 1903, doc. 294, p. 2-37; GABBA, Bassano. Sul progetto di legge per la riforma giudiziaria. Monitore dei tribunali, XLIV, 1903, p. 225 et seq.; GIANTURCO, Emanuele. Sulla riforma giudiziaria (1904). In: GIANTURCO, Emanuele. Opere giuridiche. v. I. Roma: Libreria dello Stato, 1947, p. 280 et seq.; PIOLA CASELLI, Eduardo. La magistratura. Studio sull'ordinamento giudiziario nella storia, nelle leggi straniere, nelle leggi italiane e nei progetti di riforma. Torino: UTET, 1907, p. 235 et seq.; DEGNI, Francesco. L'interpretazione della legge. op. cit., p. 129-132 e 160-161; CARNELUTTI, Francesco. Limiti del rilievo dell'error in iudicando in Corte di cassazione. Rivista del diritto commerciale, n. XIII, I, 1915, p. 801-809.
} 


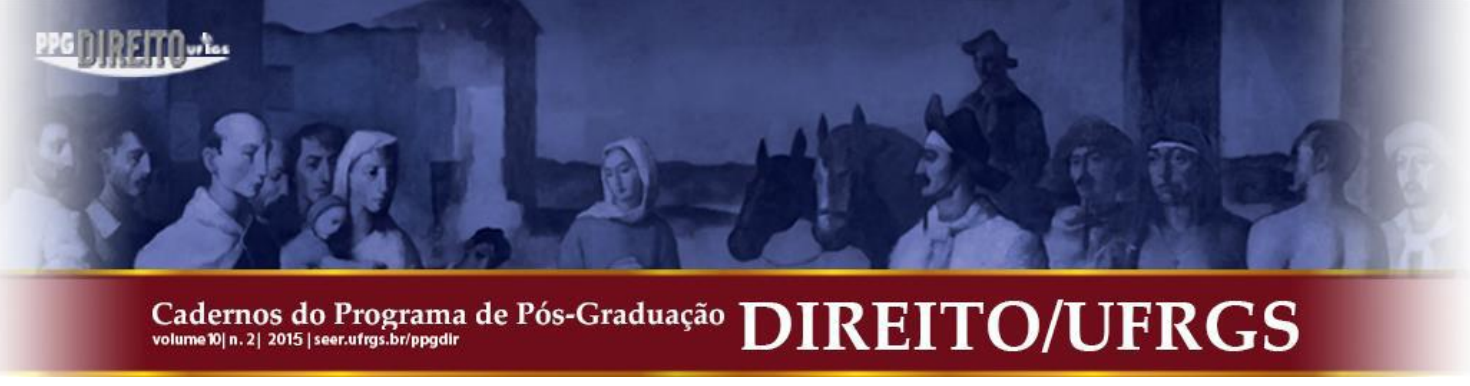

legalidade. Não há de fato uma superação do horizonte monístico nesta recuperação da jurisprudência.

A experiência jurídica demonstrou conseguir projetar além de tal horizonte somente no último cinquentenário do século XX. De fato, nesta fase se determinou uma mutação do quadro ordenatório do conjunto em consequência da introdução de um complexo de novas jurisdições no campo constitucional, comunitário e internacional (pense-se das Cortes constitucionais, da Corte de justiça europeia ou da Corte europeia de direitos do homem). A diversa constelação das condições sistemáticas na qual é chamada a operar a interpretação do direito tem também aberto horizontes novos para pensar as características dos procedimentos hermenêuticos ${ }^{50}$.

Pausamos, portanto, brevemente em conclusão, a observar os traços desta que parece a pleno título poder ser considerada como uma nova fase do direito jurisprudencial.

Tais altas Cortes em força de suas próprias prerrogativas e no desenvolvimento da própria tarefa institucional, demonstram-se capazes de incidir na formação do direito em condições de recíproca autonomia, concretizando um respiro dialético do pluralismo jurídico e superando o horizonte sistemático monístico que tinha caracterizado os Oitocentos e a primeira parte dos Novecentos. A nenhuma dessas se é dado reconhecer o poder de governar todo processo de manifestação (e ao mesmo tempo de produção) do direito vivente; qualquer expressão jurisdicional assumiu, porém, um relevo fundamental e original naquele mesmo processo.

A jurisdição constitucional, chamada a administrar a constitucionalidade das leis ${ }^{51}$ de uma posição não orgânica, mas funcionalmente coligada ao ordenamento

\footnotetext{
${ }^{50}$ Sob o plano da teoria geral veja-se, por exemplo, VOGLIOTTI, Massimo. Tra fatto e diritto. Oltre la modernità giuridica. Torino: Giappichelli, 2007, p. 210 et seq.; FERRAJOLI, Luigi. Principia iuris. Teoria del diritto e della democrazia. 1. Teoria del diritto. Roma-Bari: Laterza, 2007, em particular p. 846 et seq.; Id. Democrazia costituzionale e scienza giuridica. Diritto pubblico, n. 1, 2009, p. 1-20; ZAGREBELSKY, Gustavo. La legge e la sua giustizia. op. cit., p. 161 et seq.; OST, François; VAN DE KERCHOVE, Michel. De la pyramide au réseau. op. cit., passim; HABERMAS, Jürgen. On Law and Disagreement. Some Comments on "Interpretative Pluralism". Ratio iuris, n. 16, 2003, p. 187-194.

${ }^{51}$ Dentre outros BIGNAMI, M. Costituzione flessibile, costituzione rigida e controllo di costituzionalità in Italia (1848-1956). Milano: Giuffrè, 1997, p. 87 et seq.; FIORAVANTI, Maurizio. Costituzione e popolo sovrano. Bologna: il Mulino, 1998, p. 100-108; Id. Stato e costituzione. In: FIORAVANTI, Maurizio (org.). Lo Stato moderno in Europa. Roma-Bari: Laterza, 2002, p. 19 et seq.; Id. Costituzionalismo. Percorsi della storia e tendenze attuali. Roma-Bari: Laterza, 2009, p. 98-104 e p. 125-127; CHELI, Enzo. Il giudice delle leggi: la Corte costituzionale nella dinamica dei poteri. Bologna: il Mulino, 1999; CHELI, Enzo; DONADI, Filippo. La creazione giudiziale del diritto nelle decisioni dei giudici costituzionali. Diritto pubblico, n.1, 2007, p. 155178; RUGGERI, Antonio. SILVESTRI, Gaetano. (Org). Corte Costituzionale e Parlamento: Profili
} 


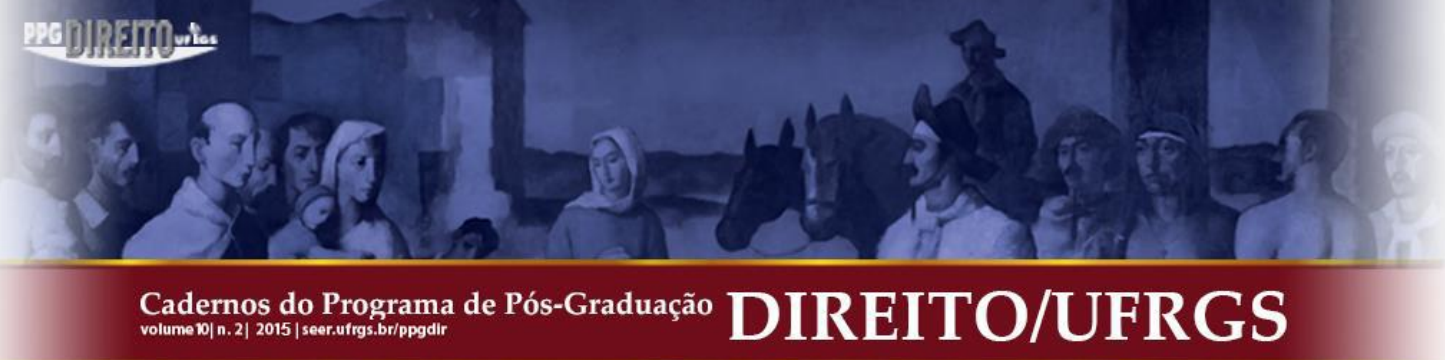

judiciário, sancionou definitivamente os fins da redução do direito na lei e favoreceu a superação da mera lógica da separação entre questão de fato e questão de direito, para introduzir uma, inédita, inspirada da relação entre jurisprudência ordinária e jurisprudência constitucional.

Por sua vez a Corte de justiça europeia e da Corte europeia de direitos do homem, embora distintas quanto à natureza, características e funções, constituíram dois polos jurisdicionais autônomos daqueles dos estados-membros singulares, mas imediatamente coligada ao direito destes, a sua jurisprudência se inseriu em modo estrutural, se não sistêmico, no circuito de produção do direito vivente ${ }^{52}$.

Para os aspectos que interessam a nossa pesquisa as dinâmicas relacionais complexas que ligam a jurisprudência ordinária daquela de tais altas cortes parecem poder ser consideradas como fenômenos unitários.

Renunciando a cada aprofundamento e sem alguma pretensão de sistematização, nos interessa aqui, porém, evidenciar alguns perfis que, neste diverso cenário, parecem caracterizar em modo inédito o direito jurisprudencial: ele surge de um campo de relações abertas entre as fontes do direito (entre leis e princípios (constitucional, comunitário ou de direito internacional), assim como também entre princípios e princípios); os desenvolvimentos deste campo de relações vem de fato determinados

Problematici e Ricostruttivi. v. 136. Milano: Giuffrè, 2000; o número monográfico da revista Ratio Juris, 16, 2003, Constitutionals Courts; ZAGREBELSKY, Gustavo. Il diritto mite. Legge, diritti, giustizia. Torino: Einaudi, 1992, passim; Id., La legge e la sua giustizia. op. cit., passim; o número monográfico do GIORNALE di Storia Costituzionale. Storia, giustizia, costituzione. Per i cinquantanni della Corte costituzionale. Macerata, n. 11, 2006; GROSSI, Paolo. Il diritto civile tra le rigidità di ieri e le mobilità di oggi. In: LOBUONO, M. (org.). Scienza giuridica privatistica e fonti del diritto. Bari: Cacucci, 2009, p. 26-30.

${ }^{52}$ Entre outros VELU, Jacques. De l'autorité jurisprudentielle des arrêts de la Cour européenne des droits de l'homme: vues de droit comparé sur des évolutions en cours. Nouveaux itinéraires en droit. Hommage à François Rigaux. Bruxelles: Bruylant, 1993, p. 527-562; FERRARESE, Maria Rosária. Il diritto europeo nella globalizzazione: fra terra e mare. Quaderni fiorentini per la storia del pensiero giuridico moderno, n. 31, 2002, p. 32 et seq. e Ibid. também os ensaios de BERNARDI, A. L'europeizzazione del diritto e la scienza penale. p. 543 et seq.; e CANNIZZARO, Enzo. Il pluralismo dell'ordinamento giuridico europeo e la questione della sovranità. Rivista di diritto internazionale, n. 1, 2010, p. 245 et seq. (veja-se deste autor também Id. Il bilanciamento fra diritti fondamentali e il nuovo articolo 117, 1 comma, Cosi. Rivista di diritto internazionale, 1/2010); na revista Quaderni fiorentini, n. 31, 2002 veja-se também o ensaio de FIORAVANTI, Maurizio. Il processo costituente europeo. Quaderni fiorentini per la storia del pensiero giuridico moderno, n. 31, 2002, p. 273 et seq. Veja-se também Id. Costituzionalismo. op. cit., p. 127-133, 156-158; PIRRONE, Pasquale. L'obbligo di conformarsi alle sentenze della Corte europea dei diritti dell'uomo. Milano: Giuffrè, 2004; GROSSI, P. Il diritto civile. op. cit., p. 30-33; DELMAS-MARTY, Mireille. Le pluralisme ordonné. Paris: Editions du Seuil, 2006; MARTINICO, Giuseppe. L'integrazione silente: la funzione interpretativa della Corte di giustizia e il diritto costituzionale europeo. Napoli, Jovene, 2009; RUOTOLO, Marco. La questione del crocifisso e la rilevanza della sentenza della Corte europea dal punto di vista del diritto costituzionale. Costituzionalismo.it, n.3, 2009, disponível em www.costituzionalismo.it; RUGGERI, L. (org.). Giurisprudenza della Corte Europea Dei Diritti Dell'uomo E Influenza Sul Diritto Interno. v. 8. Napoli: ESI, 2009. 


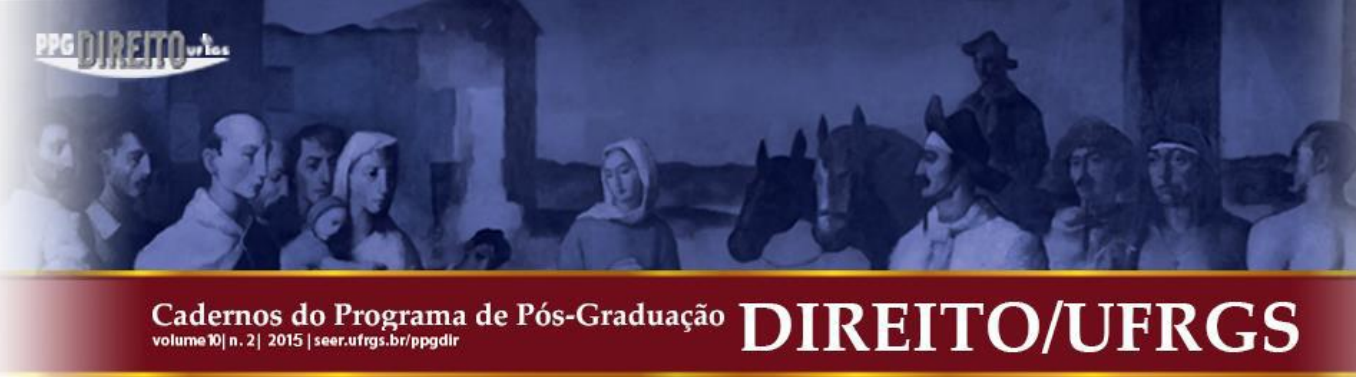

por enunciados de imediata derivação jurisprudencial ou colocados pela norma, que porém precisam passar através do filtro jurisprudencial para exprimir a sua exata importância; são antes de tudo as jurisdições que são encarregadas da tarefa (sem com isto querer diminuir a contribuição da doutrina, que ao invés da centralidade do momento jurisdicional parece trazer novas solicitações); tais jurisdições interagem entre si não sob a base de um princípio hierárquico mas segundo um princípio de reconhecimento das competências; os desenvolvimentos do direito jurisprudencial que delas resultam sempre provocadas por um concreto problema de justiça substancial e portanto surgem de uma pesquisa da dimensão jurídica material correspondente ao princípio.

Disso resulta um dato importante para o nosso itinerário, porque tais interações parecem ter a capacidade de conferir ao direito jurisprudencial uma importância nomopoiética. Considerando a nossa perspectiva histórico-jurídica, podemos dizer que, se a forma código tinha imposto uma jurisprudência que absorvia a tarefa de estabilizar o direito, agora ao invés, no novo horizonte jurisdicional (constitucional e superestatal), as funções da jurisprudência retornam a ser aquelas de atribuir graus de liberdade ao direito.

Aqui a dimensão da autonomia do direito se preenche de importâncias sistemáticas, enquanto que ao lado do perfil da autossuficiência da mediação política e ainda que afirmar simplesmente um diverso primado, aquele do direito jurisprudencial, em lugar do primado da lei - qualifica-se também por produzir na fenomenologia das fontes - afrancamentos do paradigma hierárquico e formalístico.

Por isto nos parece possível poder concluir que a saída do legalismo é um fato recente do qual o século XIX não representa o tempo de gestação, ele constitui, todavia, uma fase na qual são desenvolvidas estratégias discursivas, que, embora a favor do direito jurisprudencial, continuaram a se mover dentro de um horizonte précompreensivo monístico.

E também a partir da consciência de tal descontinuidade que é talvez possível hoje construir (e redescobrir) um espaço de significados para a autonomia do direito.

\section{REFERÊNCIAS}




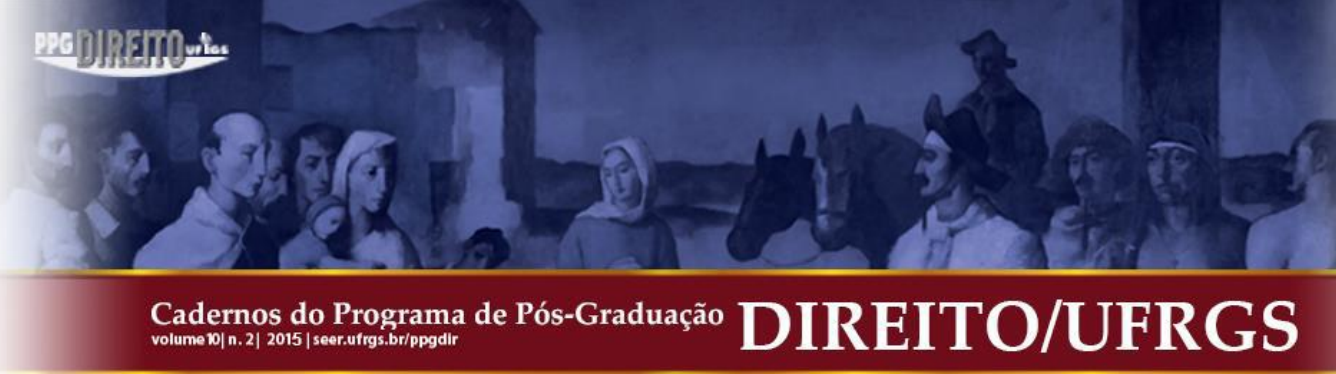

ALVAZZI DEL FRATE, Paolo. Giurisprudenza e référé législatif in Francia nel periodo rivoluzionario e napoleonico. Torino: Giappichelli, 2005.

ARAGONESES, Alfons. Recht im "fin de siècle". Briefe von Raymond Saleilles an Eugen Huber (1895-1911). Frankfurt am Main: Klostermann, 2007.

- Un jurista del Modernismo. Raymond Saleilles y los orígenes del derecho comparado. Madrid: Universidad Carlos III de Madrid, 2009.

ASQUINI, Alberto. La natura dei fatti come fonte del diritto. (1921). In: . Scritti giuridici. Padova: Cedam, 1936.

BEATSON, Jack; ZIMMERMANN, Reinhard. (Eds.). Jurists uprooted. German-speaking émigré lawyers in Twentieth-century Britain. Oxford: Oxford University Press, 2004.

BIGNAMI, Marco. Costituzione flessibile, costituzione rigida e controllo di costituzionalità in Italia (1848-1956). Milano: Giuffrè, 1997.

BIROCCHI, Italo. Alla ricerca dell'ordine. Fonti e cultura giuridica nell'età moderna. Torino: Giappichelli, 2002.

BOLZE, Albert. Über die Zulässigkeit der eigenen Auslegung von Rechtsgeschäften durch den Revisionsrichter im Civilprozess. Zeitschrift für deutschen Civilprozess, n. 14, 1890.

BONCENNE, Pierre. Théorie de la procédure civile. Paris: Videcoq, 1837.

BORSARI, Luigi. Il codice italiano di procedura civile annotato. Parte I. Roma, Napoli: UTET, 1872.

BOYENS, W. Grenze zwischen Tatsfrage und Rechtsfrage in den Zivilsenaten des Reichsgerichts. Die ersten 25 Jahre des Reichsgerichts. Leipzig: Roßberg, 1904.

BRUGI, Biagio. Senso giuridico romano e senso moderno di legalità. Atti del Real Istituto veneto di scienze lettere ed arti, n. LIX, Parte II, 1900.

. I principii generali del diritto e il diritto naturale. Archivio giuridico, n. XC, 1923. 


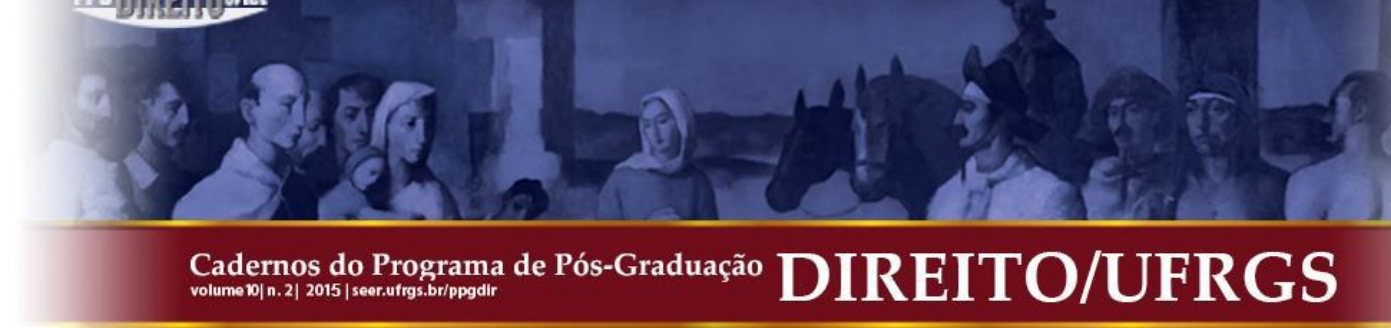

. Della proprietà. v. I. Napoli-Torino: Marghieri, UTE, 1911.

1916.

. L'analogia di diritto e il cosiddetto giudice legislatore. Il diritto commerciale, n. 35, . Introduzione enciclopedica alle scienze giuridiche e sociali. Firenze: Barbera, 1891.

. Nel regno della filosofia del diritto. Padova: Tipografia Randi, 1905.

. L'equità e il diritto positivo. Rivista internazionale di filosofia del diritto, n. III, 1923.

Logica di leggi e logica di scienza. Rivista italiana di sociologia, n. V, 1901.

L'abuso del diritto nel progetto di codice delle obbligazioni e dei contratti. Studi in onore di Alfredo Ascoli. Messina: Principato, 1931.

. Di un fondamento filosofico della così detta interpretazione storica delle leggi. Studi

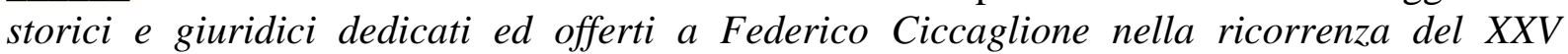
anniversario del suo insegnamento. v. II. Catania: Giannotta, 1910.

BRUSA, Emilio. BRUSA, E. Dell'unità di Cassazione penale. Annuario delle scienze giuridiche sociali e politiche, n. 4, 1883.

BÜLOW, Oskar. Über das Verhältnis der Rechtsprechung zum Gesetzesrecht. Das Recht, n. X, 1906.

. Gesetz und Richteramt. Leipzig: Duncker und Humblot, 1885.

CALAMANDREI, Piero. CALAMANDREI, Piero. La cassazione civile. I, Storia e legislazioni (1920). In: CALAMANDREI, Piero. Opere giuridiche. v. VI. Napoli, Morano, 1976.

CANNIZZARO, Enzo. Il pluralismo dell'ordinamento giuridico europeo e la questione della sovranità. Rivista di diritto internazionale, n. 1, 2010.

CAPPELLINI, Paolo. Code civil, Säkularisierung, politische Form. In: SCHUBERT, W.; SCHMOECKEL. M. (orgs.). 200 Jahre Code civil. Die napoleoniche Kodifikation in 


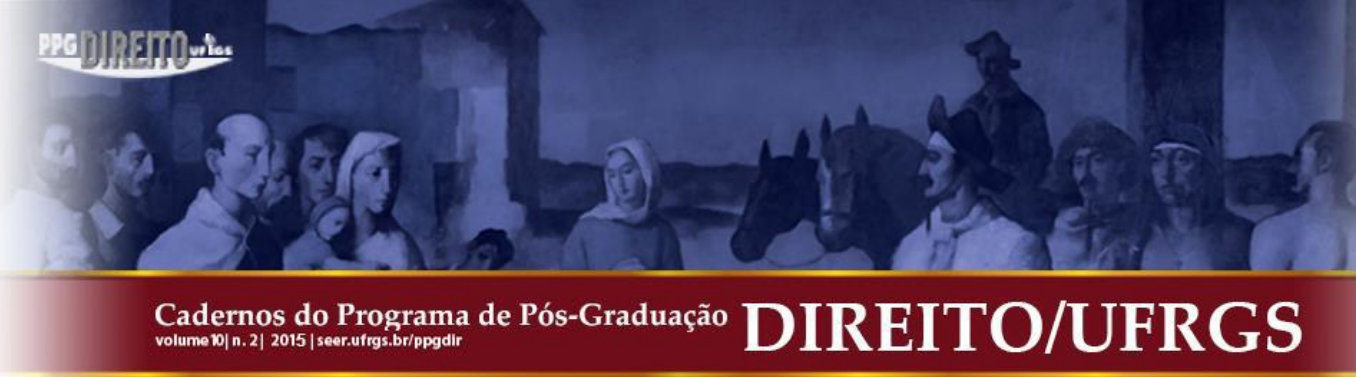

Deutschland und Europa. Köln, Weimar, Wien: Böhlau, 2005.

CARNELUTTI, Francesco. Limiti del rilievo dell'error in iudicando in Corte di cassazione. Rivista del diritto commerciale, n. XIII, I, 1915.

CARONI, Pio. Il codice rinviato. Resistenze europee all'elaborazione e alla diffusione del modello codicistico. In: CAPPELLINI, P.; SORDI, B. (orgs.). Codici, una riflessione di fine millennio. Milano: Giuffrè, 2002.

1991.

Il mito svelato: Eugen Huber. Zeitschrift für schweizerisches Recht, n. 132,

CAVANNA, Adriano. Storia del diritto moderno in Europa. Le fonti e il pensiero giuridico. v. 2. Milano: Giuffrè, 2005.

CAZZETTA, Giovani. Codice civile e identità giuridica nazionale. Percorsi e appunti per una storia delle codificazioni moderne. Torino: Giappichelli, 2011.

Responsabilità aquiliana e frammenti del diritto comune civilistico (1865-

1914). Milano: Giuffrè, 1991.

CHELI, Enzo. Il giudice delle leggi: la Corte costituzionale nella dinamica dei poteri. Bologna: il Mulino, 1999.

; DONADI, Filippo. La creazione giudiziale del diritto nelle decisioni dei giudici costituzionali. Diritto pubblico, n.1, 2007.

CIPRIANI, Franco. La scomparsa di Carlo Lessona e La cassazione di Piero Calamandrei. Il giusto processo civile, 1, 2008.

. Storie di processualisti e di oligarchi: la procedura civile nel Regno d'Italia, 18661936. Milano: Giuffrè, 1991.

COSTA, Pietro. L'interpretazione della legge: François Gény e la scienza giuridica del Novecento. Quaderni fiorentini per la storia del pensiero giuridico moderno, n. 20, 1991.

COVIELLO, Leonardo. Dei moderni metodi d'interpretazione della legge. S. Maria C. V.: Cavotta, 1908.

COVIELLO, Nicola. Manuale di diritto civile italiano. Milano: Società Editrice Libraria, 


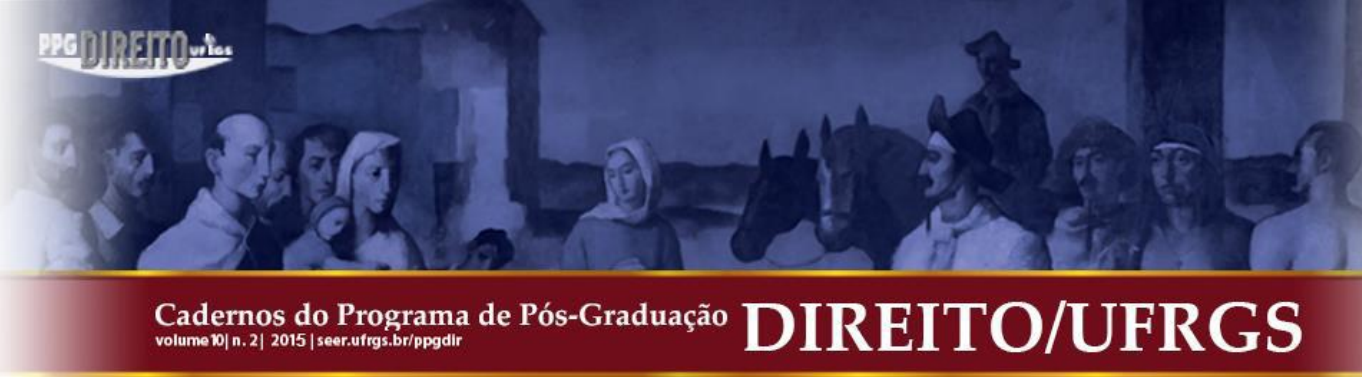

1915.

CRÉPON, Théophile. Du pourvoi en cassation en matière civile. v. I. Paris: Larose \& Forcel, 1892.

DE LA GRASSERIE, Raoul. De la fonction et des juridictions de cassation en législation comparée (évolution, comparaison critique, réforme). Paris: LGDJ, 1911.

DEGNI, Francesco. L'interpretazione della legge. Napoli: Jovene, 1909.

DELMAS-MARTY, Mireille. Le pluralisme ordonné. Paris: Editions du Seuil, 2006.

EHRLICH, Eugen. Freie Rechtsfindung und freie Rechtswissenschaft. Leipzig: Hirschfeld, 1903.

. Gesetz und lebendes Recht. Vermischte kleinere Schriften. Berlin: Duncker \& Humblot, 1986.

ENDEMANN, Wilhelm. Der deutsche Civilprozeß. Erläuterungen des Gerichtsverfassungsgesetzes und der Civilprozessordnung des deutschen Reichs. Band II. Berlin: Weidemannsche, 1879.

ERYTHROPEL. Zur Lehre von der Revision. Zeitschrift für deutschen Civilprozess, n. III, 1881.

FALK, U.; MOHNHAUPT, H. (orgs.). Das Bürgerliche Gesetzbuch und seine Richter. Zur Reaktion der Rechtsprechung auf die Kodifikation des deutschen Privatrechts (1896-1914). Frankfurt am Main: Klostermann, 2000.

FAYE, Ernest. La Cour de cassation, Paris, 1903. Ristampa, Paris: Auvermann. 1970.

FEBBRAJO, Alberto. Eugen Ehrlich: dal diritto libero al diritto vivente. Sociologia del diritto, 1982.

FERRAJOLI, Luigi. Democrazia costituzionale e scienza giuridica. Diritto pubblico, n. 1, 2009.

Principia iuris. Teoria del diritto e della democrazia. 1. Teoria del diritto. Roma- 


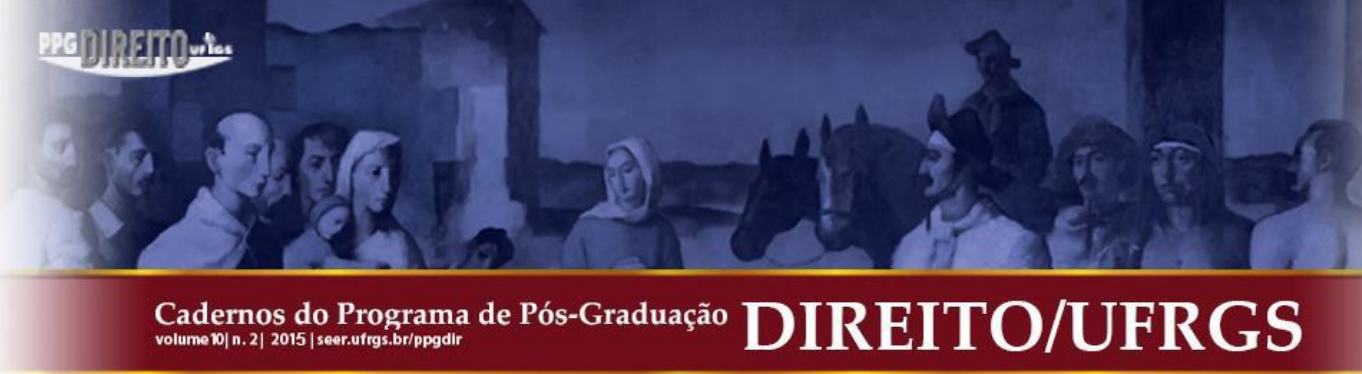

Bari: Laterza, 2007.

FERRARA, Francesco. Potere del legislatore e funzione del giudice. Rivista di diritto civile, n. III, 1911.

FERRARESE, Maria Rosária. Il diritto europeo nella globalizzazione: fra terra e mare. Quaderni fiorentini per la storia del pensiero giuridico moderno, n. 31, 2002.

FIORAVANTI, Maurizio. Costituzionalismo. Percorsi della storia e tendenze attuali. RomaBari: Laterza, 2009.

Costituzione e popolo sovrano. Bologna: il Mulino, 1998.

Il processo costituente europeo. Quaderni fiorentini per la storia del pensiero giuridico moderno, n. 31, 2002.

Stato e costituzione. In: FIORAVANTI, Maurizio (org.). Lo Stato moderno in Europa. Roma-Bari: Laterza, 2002.

GABBA, Bassano. Sul progetto di legge per la riforma giudiziaria. Monitore dei tribunali, XLIV, 1903.

GAUDEMET, Yves. Le code civil, "Constitution civile de la France". In: LEQUETTE, Y.; LEVENEUR, L. (orgs.). 1804-2004 Le Code civil, Un passé, un présent, un avenir. Paris: Dalloz, 2004.

GÉNY, François. Méthode d'interprétation et sources en droit privé positif. 2. ed. v. I. Paris: LGDJ, 1919.

GEYER, Stefan. Den Code civil "richtiger" auslegen. Der zweite Zivilsenat des Reichsgerichts und das französische Zivilrecht. Frankfurt am Main: Klostermann, 2009.

GIANTURCO, Emanuele. Sulla riforma giudiziaria (1904). In: v. I. Roma: Libreria dello Stato, 1947 . Opere giuridiche.

GIORNATA Lincea In Ricordo di Lodovico Mortara. Roma: Accademia nazionale dei Lincei, v. 136, 1998. 17 Abr. 1997. 


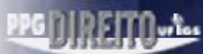

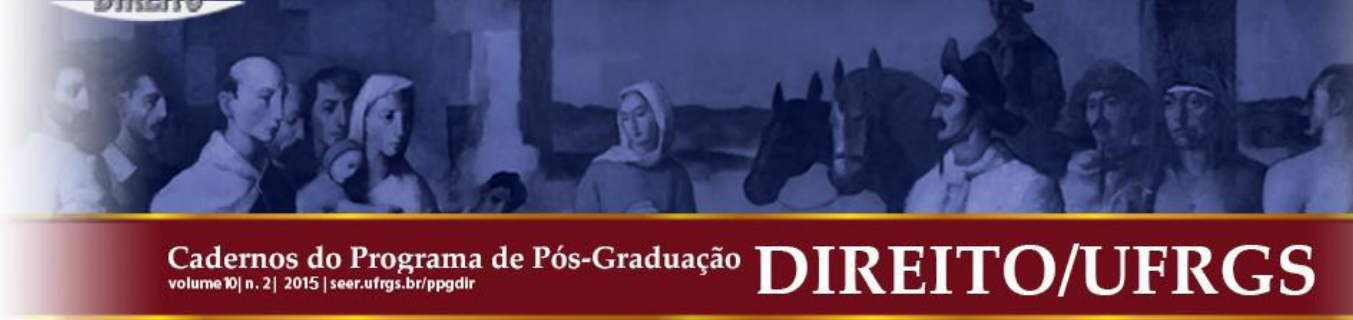

GIORNALE di Storia Costituzionale. Storia, giustizia, costituzione. Per i cinquantanni della Corte costituzionale. Macerata, n. 11, 2006.

GLAESER, Mathias. Lehre und Rechtsprechung im französischen Zivilrecht des 19. Jahrhunderts. Frankfurt am Main: Klostermann, 1996.

GLÖCKNER, Hans Peter. Die Rechtsprechung des Reichsgerichts: Thema mit Variationen. Ius commune, $\mathrm{n}$. XXV, 1998.

GROSSI, Paolo. L'Europa del diritto. Uno storico del diritto in colloquio con gli storici del pensiero economico. Il pensiero economico italiano, XVI, 2008.

- Il coraggio della moderazione (specularità dell'itinerario riflessivo di Vittorio Polacco). Quaderni fiorentini per la storia del pensiero giuridico moderno, n. 18, 1989.

n. 20, 1991.

Ripensare Gény. Quaderni fiorentini per la storia del pensiero giuridico moderno,

. L'avvio di un itinerario scientifico (una lettura del primo volume degli Scritti giuridici di Salvatore Pugliatti). Rivista di diritto civile, n. LV, 4, 2009.

. Scienza giuridica italiana. Un profilo storico, 1860-1950. Milano: Giuffrè, 2000.

Il diritto civile tra le rigidità di ieri e le mobilità di oggi. In: LOBUONO, M. (org.). Scienza giuridica privatistica e fonti del diritto. Bari: Cacucci, 2009.

HABERMAS, Jürgen. On Law and Disagreement. Some Comments on "Interpretative Pluralism". Ratio iuris, n. 16, 2003.

HALPÉRIN, Jean-Louis. Histoire du droit privé français depuis 1804. Paris: PUF, 1996.

Le Tribunal de cassation et les pouvoirs sous la Révolution (1790-1799). Paris:

LGDJ, 1987.

. L'impossible code civil. Paris: PUF, 1992.

HELLWIG, Konrad. System des deutschen Zivilprozessrechts. Teil I, Leipzig: Deichert. 1912. Ristampa: Aalen, Scientia, 1980. 


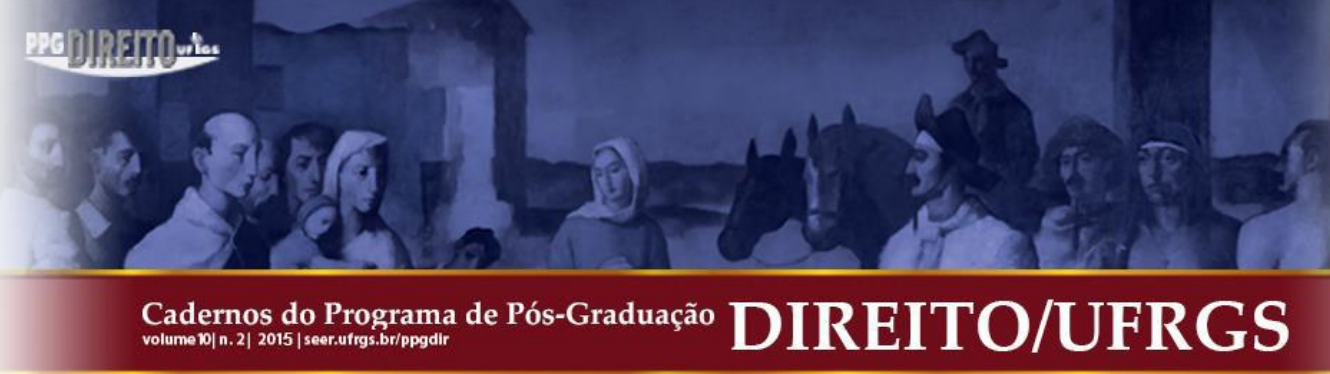

MARCHETTI, Raffaele. Terza istanza e cassazione. Relazioni e deliberazioni del Circolo legale romano sulle tesi proposte al primo Congresso giuridico italiano. Roma: Mugnoz, 1872.

MARINO, Giovanni. Biagio Brugi e il "metodo storico" nella determinazione dei principi del diritto. Index, n. 16, 1988.

Positivismo e giurisprudenza. Biagio Brugi e la congiunzione di scuola storica e filosofia positiva. Napoli: ESI, 1987.

MARTINICO, Giuseppe. L'integrazione silente: la funzione interpretativa della Corte di giustizia e il diritto costituzionale europeo. Napoli, Jovene, 2009.

MARTY, Gabriel. La distinction du fait e du droit. Essai sur le pouvoir et le contrôle de la Cour de cassation sur les juges du fait. Paris: Sirey, 1929.

MECCARELLI, Massimo. Le Corti di cassazione nell'Italia unita. Profili sistematici e costituzionali della giurisdizione in una prospettiva comparata. Milano: Giuffrè, 2005.

Cassation, révision et tâche de la juridiction: une comparaison entre France, Allemagne et Italie au cours du XIXe siècle. In: HAUTEBERT, J.; SOLEIL, S. (orgs.). Modèles français, enjeux politiques et élaboration des grandes textes de procédure en Europe. Paris: Editions juridiques et techniques, 2007.

Giurisdizione penale e legalità in Lodovico Mortara. Quaderni fiorentini per la storia del pensiero giuridico moderno, n. 36, 2007.

Un senso moderno di legalità. Il diritto e la sua evoluzione nel pensiero di Biagio Brugi. Quaderni fiorentini per la storia del pensiero giuridico moderno, n. 30, 2001.

MICELI, Vincenzo. Sul principio di equità. In: Studi di diritto romano, di diritto moderno e di storia del diritto pubblicati in onore di Vittorio Scialoja nel XXV anniversario del suo insegnamento. v. II. Milano: Hoelpi, 1905.

I principi generali del diritto. Rivista di diritto civile, n. XV, 1923.

MONTAZEL, Laurence. Entre fait et droit: histoire d'un pouvoir judiciaire. Les techniques de la cassation civile en France et en Allemagne au XlXème siècle. Frankfurt am Main: Klostermann, 1998. 


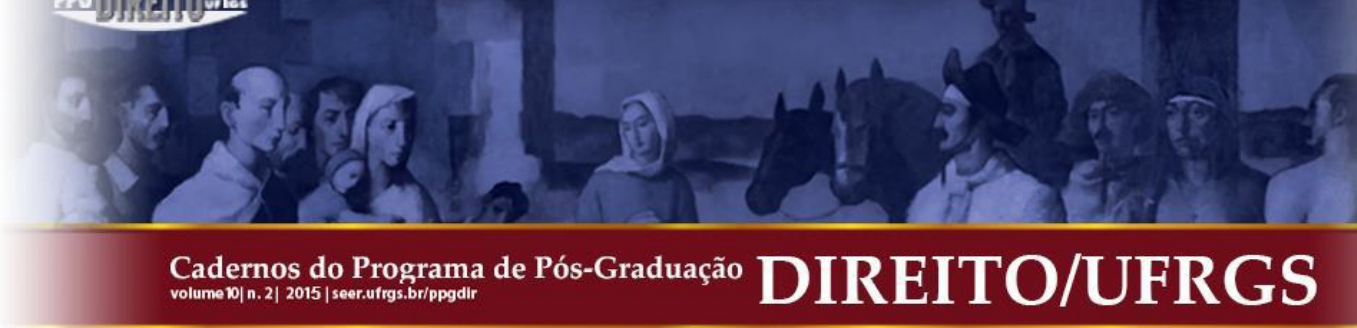

MORTARA, Lodovico. Commentario del codice e delle leggi di procedura civile. 2. ed. v. I. Teoria e sistema della giurisdizione civile. Milano: Vallardi, (s.d.). Istituzioni di ordinamento giudiziario. Firenze: Barbera, 1896.

MUSCHELER, Karlheinz. Relativismus und Freirecht. Ein Versuch über Hermann Kantorowicz. Heidelberg: Müller, 1984.

OGOREK, Regina. Richterkönig oder Subsumtionsautomat? Zur Justiztheorie in 19. Jahrhundert. Frankfurt am Main: Klostermann, 1986.

ORLANDO, Vittorio Emanuele. Sull'unificazione della Cassazione civile. Palermo: F.lli Vena, 1893.

OST, François; VAN DE KERCHOVE, Michel. De la pyramide au réseau? Pour une théorie dialectique du droit. Bruxelles: Facultés universitaires Sant-Louis, 2002.

PETIT, Carlos. Lambert en la Tour Eiffel, o el derecho comparado de la Belle Epoque. La comparazione giuridica tra Ottocento e Novecento. In memoria di Mario Rotondi. Milano: Istituto lombardo di scienze e lettere, 2001.

PIOLA CASELLI, Eduardo. La magistratura. Studio sull'ordinamento giudiziario nella storia, nelle leggi straniere, nelle leggi italiane e nei progetti di riforma. Torino: UTET, 1907.

PIRRONE, Pasquale. L'obbligo di conformarsi alle sentenze della Corte europea dei diritti dell'uomo. Milano: Giuffrè, 2004.

POLACCO, Vittorio. Le cabale del mondo legale. (1908). In: Opere minori. Parte prima, Problemi di legislazione. Modena: Università degli Studi di Modena, 1928.

Penombre e sorprese nella formazione delle leggi (1914). In: POLACCO, Vittorio. Opere minori. Parte prima, Problemi di legislazione. Modena: Università degli Studi di Modena, 1928.

RAGGI, Luigi. Appunti sull'interpretazione progressiva. Rivista internazionale di filosofia del diritto, n. III, 1923. 


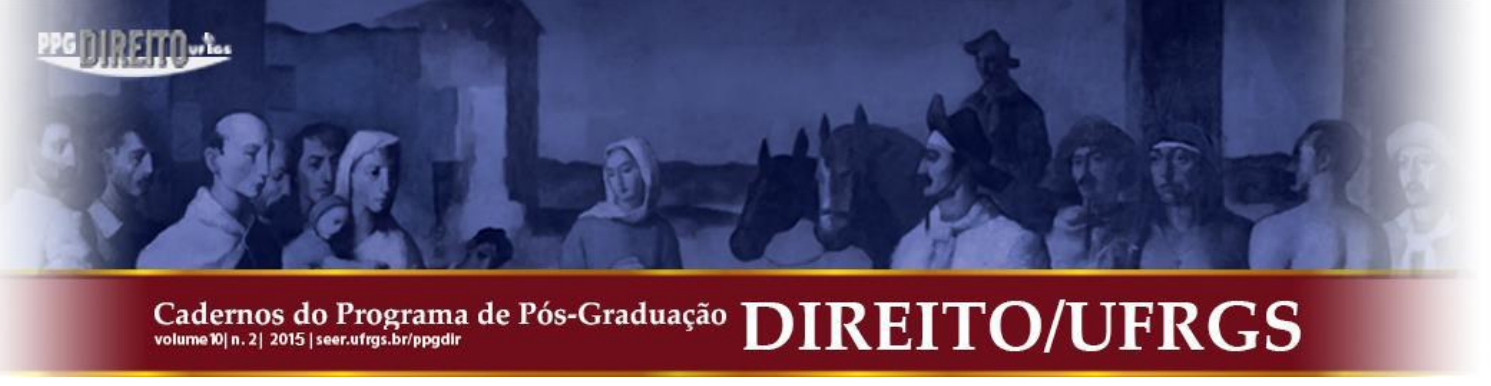

REHBINDER, Manfred. Die Begründung der Rechtssoziologie durch Eugen Ehrlich. Berlin: Duncker \& Humblot, 1986.

ROYER, Jean-Pierre. Histoire de la justice en France de la monarchie absolue à la République. Paris: PUF, 1995.

RUCKERT, Joachim. Der Geist des Rechts in Jherings"Geist" und Jherings "Zweck". Rechtsgeschichte, n. 5, 2004.

RUGGERI, Antonio. SILVESTRI, Gaetano. (Org). Corte Costituzionale e Parlamento: Profili Problematici e Ricostruttivi. v. 136. Milano: Giuffrè, 2000.

RUGGERI, L. (org.). Giurisprudenza della Corte Europea Dei Diritti Dell'uomo E Influenza Sul Diritto Interno. v. 8. Napoli: ESI, 2009.

RUOTOLO, Marco. La questione del crocifisso e la rilevanza della sentenza della Corte europea dal punto di vista del diritto costituzionale. Costituzionalismo.it, n.3, 2009. Disponível em www.costituzionalismo.it

SABBIONETI, Marco. Democrazia sociale e diritto privato. La terza Repubblica di Raymond Saleilles (1855-1912). Milano: Giuffrè, 2011.

Un Cattolico "Protestante". La crisi della separazione tra Stato e Chiesa nelle lettere inedite di Raymond Saleilles a Louis Birot (1906-1909). Torino: Giappichelli, 2005.

SALOMÉ, Yvonne. Les pouvoirs de contrôle de la Cour de cassation en matière de conflits des lois. Paris, Sirey, 1938.

SANGIORGI, Antonino. Relazione della Commissione istituita per studiare un Progetto di costituzione della suprema magistratura del Regno. Il circolo giuridico, v. XXII, 1891.

SATTA, Salvatore. Attualità di Lodovico Mortara (1968). Soliloqui e colloqui di un giurista. Nuoro: Ilisso, 2004.

SCHMIDT, Richard. Lehrbuch des deutschen Zivilprozessrechts. Leipzig: Duncker \& Humblot, 1910.

SCHRÖDER, Jan. Gesetzesauslegung und Gesetzesumgehung. Das Umgehungsgeschäft in der rechtswissenschaftlichen Doktrin von der Spätaufklärung bis zum Nationalsozialismus. 


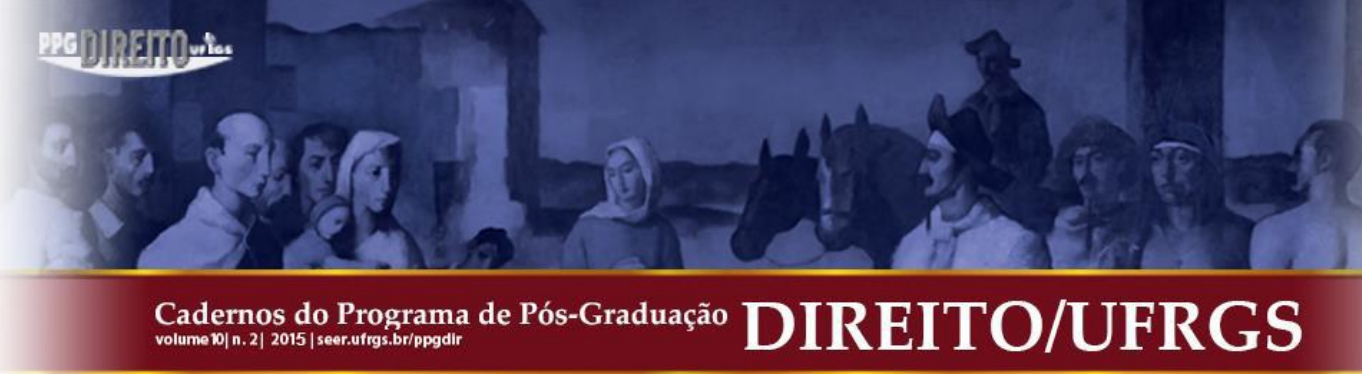

Paderborn, München, Wien, Zürich: Schöningh, 1985.

SCHRÖDER, Rainer. Die deutsche Methodendiskussion um die Jahrhundertwende: Wissenschafts- theoretische Präzisierungsversuche oder Antworten auf den Funktionswandel von Recht und Justiz. Rechtstheorie, n. 19, 1988.

SCIUMÈ, A. I principii generali del diritto nell'ordine giuridico contemporaneo (18371942). Torino: Giappichelli, 2002.

Fra revisione e cassazione: modelli di organizzazione giudiziaria e politica dell'unificazione nella Lombardia postunitaria. Ius mediolani. Studi di storia del diritto milanese offerti dagli allievi a Giulio Vismara. Milano: Giuffrè, 1996.

SILBERG, Sebastian. Hermann Kantorowicz und die Freirechtsbewegung. Berlin: Logos, 2004.

SIMONCELLI, Vincenzo. Le presenti difficoltà della scienza del diritto civile (1890). In: . Scritti giuridici. v. I. Roma: Foro italiano, 1938.

SOLIMANO, Stefano. L'edificazione del diritto privato italiano: dalla restaurazione all'Unità. Forum Historiae Iuris, 17. Mai 2005. Disponível em: http://www.forhistiur.de.

"Il letto di Procuste". Diritto e politica nella formazione del codice civile unitario. I progetti Cassinis, (1860-1861). Milano: Giuffrè, 2003.

. Tra esegesi e sistema? Cultura giuridica e metodo scientifico di Francesco Saverio Bianchi (1827-1908). Ius. Rivista di scienze giuridiche, n. 1-2, 2010.

SONNENSCHMIDT, Friedrich Hermann. Über das Rechtsmittel der Revision nach der Zivilprozessordnung für das deutsche Reich von 30. Januar 1877. Zeitschrift für deutschen Civilprozess, n. II, 1880.

SPECIALE, Giuseppe. Antologia giuridica. Laboratori e rifondazioni di fine Ottocento. Milano: Giuffrè, 2001.

STAMPE, ERNST. Die Freirechtsbewegung. Gründe und Grenzen ihrer Berechtigung, Berlin: Franz Wahlen, 1911.

TARUFFO, Michele. Cassazione e revisione: un problema nella storia delle istituzioni giudiziarie. Il vertice ambiguo. Bologna: il Mulino, 1991. 


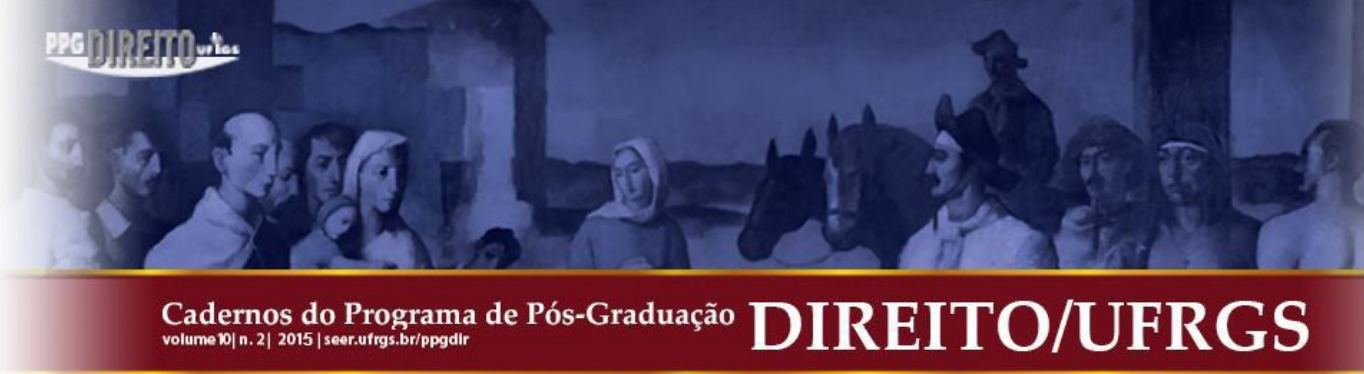

VELU, Jacques. De l'autorité jurisprudentielle des arrêts de la Cour européenne des droits de l'homme: vues de droit comparé sur des évolutions en cours. Nouveaux itinéraires en droit. Hommage à François Rigaux. Bruxelles: Bruylant, 1993.

VOGL, Stefan. Soziale Gesetzgebungs- politikfreie Rechtsfindung und soziologische Rechtswissenschaft bei Eugen Ehrlich. Baden-Baden: Nomos, 2003.

VOGLIOTTI, Massimo. Tra fatto e diritto. Oltre la modernità giuridica. Torino: Giappichelli, 2007.

WEISSMANN, Jakob. Einheitliches Recht und einheitliche Rechtsprechung. Zeitschrift für deutschen Civilprozess, IX, 1886.

WIEACKER, Franz. Storia del diritto privato moderno. v. II. Milano: Giuffrè, 1980.

ZAGREBELSKY, Gustavo. Il diritto mite. Legge, diritti, giustizia. Torino: Einaudi, 1992.

La legge e la sua giustizia. Bologna: il Mulino, 2008.

ZANARDELLI, G. Relazione al disegno di legge sull'ordinamento giudiziario. Atti della Camera dei Deputati. Documenti, Legislatura XXI, 2a Sessione 1902-1903, Roma, 1903.

ZIMMERMANN, R. Das Bürgerliche Gesetzbuch und die Entwicklung des Bürgerlichen Rechts. In: SCHMOECKEL, M.; RÜCKERT, J.; ZIMMERMANN, R. (orgs.). Historischkritischer Kommentar zum BGB. Tübingen: Mohr Siebeck, 2003.

Submissão: 30/10/2015 Aceito para Publicação: 31/10/2015 
